PEDRO FELIPE COUTO VIEIRA

\title{
UTILIZAÇÃO DE INSULINA PARA TRATAMENTO DE DIABETES NO BRASIL
}

Brasília, Brasil

2016 
UNIVERSIDADE DE BRASILIA

FACULDADE DE CIÊNCIAS DA SAÚDE

PROGRAMA DE PÓS-GRADUAÇÃO EM SAÚDE COLETIVA

\section{DISSERTAÇÃO DE MESTRADO \\ UTILIZAÇÃO DE INSULINA PARA TRATAMENTO DE DIABETES NO BRASIL}

PEDRO FELIPE COUTO VIEIRA

Dissertação apresentada como requisito parcial para a obtenção do título de mestre em Saúde Coletiva pelo Programa de Pós-Graduação em Saúde Coletiva, Universidade de Brasília.

Orientador: Prof. Dra. Noemia Urruth Leão Tavares

Brasília, Brasil.

2016 
PEDRO FELIPE COUTO VIEIRA

UTILIZAÇÃO DE INSULINA PARA TRATAMENTO DE DIABETES NO BRASIL

Dissertação apresentada como requisito parcial para a obtenção do título de mestre em Saúde

Coletiva pelo Programa de Pós-Graduação em Saúde Coletiva, Universidade de Brasília.

Aprovado em 29 de abril de 2016

\section{BANCA EXAMINADORA}

Profa. Dra. Noemia Urruth Leão Tavares

Universidade de Brasília, UnB

Presidente

Prof. Dr. Mariana Sodário Cruz

Universidade de Brasília, UnB

Membro Interno

Prof. Dr. Paulo Sergio Dourado Arrais

Universidade Federal do Ceará, UFC

Membro Externo

Prof. Dra. Dayde Lane Mendonça Silva

Universidade de Brasília, UnB

Suplente 
À Deus, primeiramente, que me deu forças para completar mais essa etapa da vida. Aos meus Pais, que sempre alimentaram esse sonho junto comigo. Aos meus irmãos, que sempre me deram força. Aos meus familiares e amigos, que sempre torceram por mim. 


\section{AGRADECIMENTOS}

Considerando esta dissertação como resultado de uma caminhada que não começou em Brasília, agradecer pode não ser tarefa fácil, nem justa. Para não correr o risco da injustiça, agradeço de antemão a todos que de alguma forma passaram pela minha vida e contribuíram para a construção de quem sou hoje.

Agradeço em primeiro lugar a Deus, que iluminou o meu caminho durante esta caminhada.

Dedico esta, bem como todas as minhas demais conquistas, aos meus amados pais (João Camelo e Socorro Couto), que me educaram, me deram amor e investiram nos meus estudos; aos meus irmãos (João Emanuel e Paulo Henrique), que sempre me deram força para continuar a jornada; e minha sobrinha (Bianca), e dizer que os amo muito.

Agradeço a minha orientadora e coordenadora Professora Noemia Tavares, que teve paciência e me ajudou bastante a concluir este trabalho e vem me ensinando cada vez mais sobre a fascinante área da Assistência Farmacêutica. Agradeço a Karen Costa, que, além de ter sido uma grande amiga, se tornou uma referência de ética e trabalho.

Agradeço aos amigos e colegas de trabalho da Coordenação Geral de Assistência Farmacêutica Básica, que, sem dúvida, serão grandes profissionais. Em especial o farmacêutico Evandro Medeiros, que me deu suporte durante todo o período de realização do curso, e Maurício Vasconcelos, pela parceria e ajuda diária. Também não posso deixar de agradecer as minhas colegas Letisa Nora e Patrícia Silveira pela parceria diária tanto no trabalho como no mestrado.

Aos meus amigos de Fortaleza, de Brasília e do Brasil afora, pelo companheirismo, pelo incentivo, força, amizade, carinho... Quero levar vocês pra minha vida toda. À todos os mestres que tive a oportunidade de aprender e, sem dúvidas, me proporcionaram uma formação acadêmica diferenciada, bem mais humana, respaldada na Saúde Pública e na Luta por um SUS 100\% Público, Gratuito e de Qualidade. 


\section{RESUMO}

O tratamento da Diabetes Mellitus (DM) é complexo e um dos seus objetivos centrais é a obtenção de valores glicêmicos o mais próximo da normalidade. Seu tratamento pode ou não estar associado à prescrição de medicamentos ou à reposição insulínica. No Brasil, segundo a Pesquisa Nacional de Saúde (PNS) 2013, estima-se uma prevalência de diabetes de 6,2\%, atingindo 9 milhões de brasileiros. O presente estudo teve por objetivo descrever a prevalência de diabetes, indicação médica e utilização de insulina pela população adulta brasileira, segundo variáveis sociodemográficas. Além disso, caracterizar os tipos de insulina mais utilizados no Brasil. Os dados analisados no presente estudo são oriundos da Pesquisa Nacional sobre Acesso, Utilização e Promoção do Uso Racional de Medicamentos (PNAUM), inquérito domiciliar de base populacional, de delineamento transversal. A prevalência referida de diabetes na população adulta foi de 6,8\% (IC95\%=6,4-7,2\%) e destes, $17,5 \%$ referiram indicação médica para utilização de Insulina, o que representa 1,5 milhões de diabéticos. Dos diabéticos com indicação médica, 87,6\% relataram usar insulina diariamente. Observou-se que a região Norte apresentou menor prevalência de indicação médica de insulina, em contramão, o sudeste apresentou maior prevalência. Foi verificada uma maior prevalência de uso de insulina pelas mulheres e entre os pertencentes a grupos etários de maior idade com diferenças entre as grandes regiões do país. O uso das insulinas humanas (NPH e Regular) apresentou maior percentual de uso $(88 \%$, IC95\%=80,8-92,7) em relação às insulinas análogas. Os resultados encontrados demonstram a alta prevalência de utilização de insulinas para tratamento da Diabetes pela população adulta brasileira. Entretanto, as diferenças entre as grandes regiões do país que podem refletir desigualdades no processo de cuidado aos pacientes portadores desses agravos, incluído o tratamento medicamentoso.

Palavras chaves: Insulina; Diabetes Mellitus; Assistência Farmacêutica; Uso de medicamentos; Sistema Único de Saúde. 


\begin{abstract}
Treatment of Diabetes Mellitus (DM) is complex and one of its main objectives is to obtain normal blood glucose levels as close as possible.. DM's treatment may or may not be associated with prescription medications or insulin replacement. In Brazil, according to the National Health Survey (PNS) in 2013, diabetes has an estimated prevalence of $6.2 \%$, affecting to 9 million Brazilians. This study aimed to describe the prevalence of diabetes, medical indication and use of insulin by the Brazilian adult population, according to sociodemographic variables. Furthermore, to characterize the types of insulin are most involved in Brazil. The data analyzed in this study is from the National Survey on Access, Use and Promotion of Rational Use Medicines (PNAUM), household survey populationbased cross-sectional study. Prevalence of diabetes in adults was $6.8 \%$ (95\% CI $=6.4$ to $7.2 \%$ ) in wich, $17.5 \%$ reported medical indication for use of insulin, representing 1.5 million diabetics. $87.6 \%$ Diabetics with medical indication reported using insulin daily. We observed that the North showed a lower prevalence of medical indication of insulin while Southeast presented the highest prevalence. Women and oldest age people showed a higher prevalence of insulin use with differences between the major regions of the country. The use of human insulins (NPH and Regular) showed higher usage percentage (88\%, CI 95\% = 80.8 to 92.7 ) compared with analogues insulin. Results showed the high prevalence of use of insulin for treatment of diabetes by the Brazilian adult population. However, the differences between the major regions of the country may reflect inequalities in the care process to patients with these conditions, including drug treatment.
\end{abstract}

Key words: Insulin; Diabetes Mellitus; Pharmaceutical services; Drug Utilization; Unified Health System. 


\section{LISTA DE TABELAS}

Tabela 1 - Prevalência de diabetes segundo características demográficas e socioeconômicas na população brasileira. PNAUM, BRASIL, 2014 40

Tabela 2 - Prevalência dos usuários que apresentam indicação médica para uso de insulina.

PNAUM, BRASIL, 2014. 42

Tabela 3 - Prevalência dos usuários que utilizam insulina (N=428). PNAUM, BRASIL, 2014 44 


\section{LISTA DE ILUSTRAÇÕES}

Quadro 1 - Domínios regionais e demográficos da amostra.................................................... 33

Figura 1 - Fluxo de blocos respondidos pelos Adultos. ....................................................... 32

Gráfico 1 - Prevalência de uso de insulinas na população de 20 anos ou mais de acordo com

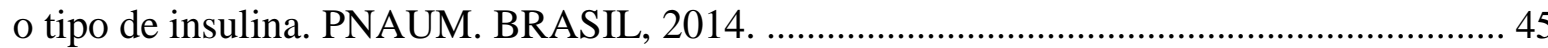




\section{LISTA DE ABREVIATURAS E SIGLAS}

A1C Hemoglobina Glicada

ADA American Diabetes Association

AF Assistência Farmacêutica

APS Atenção Primária à Saúde

CNES Cadastro Nacional de Estabelecimentos de Saúde

CONITEC Comissão Nacional de Incorporação de Tecnologias no SUS

DAF Departamento de Assistência Farmacêutica

DCNT Doença Crônica Não-Transmissíveis

DM Diabetes Mellitus

ESF Estratégica Saúde da Família

HIPERDIA Plano de Reorganização da Atenção à Hipertensão Arterial e ao Diabetes

\section{Mellitus}

IBGE Instituto Brasileiro de Geografia e Estatística

IDF Internacional Diabetes Federation

MS Ministério da Saúde

OMS Organização Mundial de Saúde

PFPB Programa Farmácia Popular do Brasil

PNAD Pesquisa Nacional por Amostra de Domicílios

PNAF Política Nacional de Assistência Farmacêutica

PNAUM Pesquisa Nacional sobre Acesso, Utilização e Promoção do Uso

Racional de Medicamentos

PNM Política Nacional de Medicamentos

PNS Pesquisa Nacional de Saúde

POF Pesquisa de Orçamentos familiares

RAS Redes de Atenção à Saúde

RENAME Relação Nacional de Medicamentos Essenciais

SBD $\quad$ Sociedade Brasileira de Diabetes

SIPD Sistema Integrado de Pesquisas Domiciliares

SUS Sistema Único de Saúde

VIGITEL Vigilância de Fatores de Risco e Proteção para Doenças Crônicas

por Inquérito Telefônico 


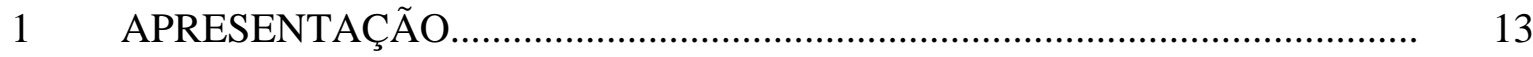

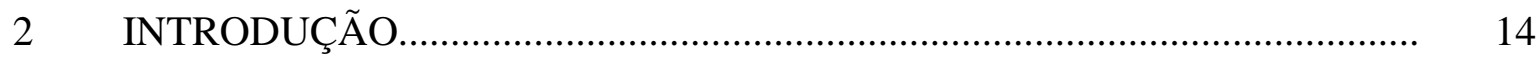

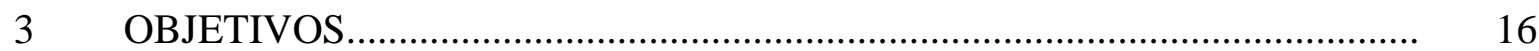

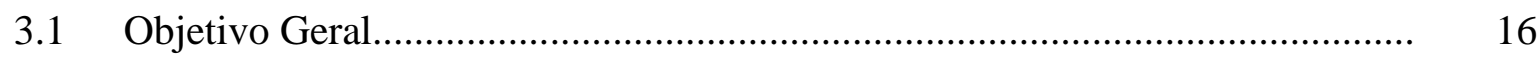

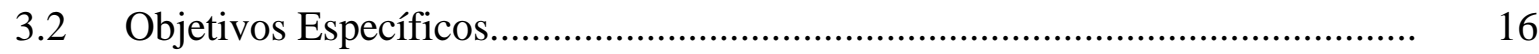

4 REFERENCIAL TEÓRICO....................................................................... 17

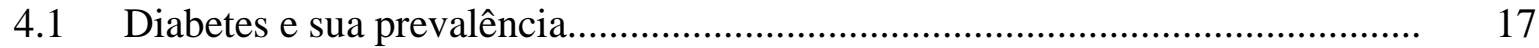

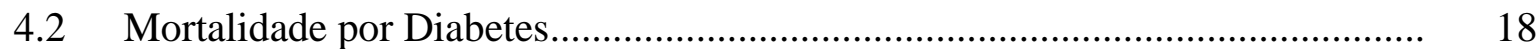

4.3 Tratamento Medicamentoso para controle de Diabetes...................................... 19

4.4 Acesso a medicamentos............................................................................. 20

4.5 Pragramas e Políticas de acesso ao tratamento de Diabetes no Brasil................. 23

4.6 Monitoramento das DCNT......................................................................... 27

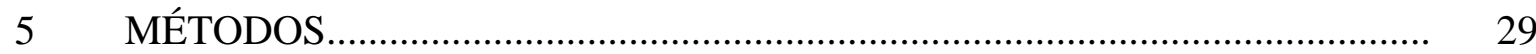

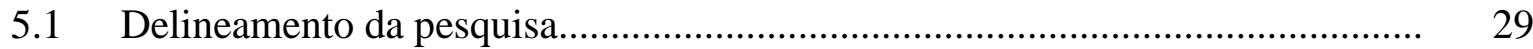

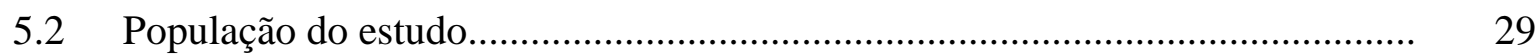

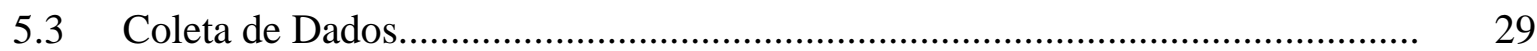

5.4 Amostra e amostragem............................................................................. 33

5.5 Análise de dados........................................................................................ 36

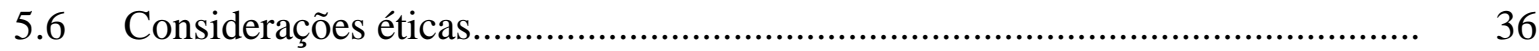

$6 \quad$ RESULTADOS E DISCUSSÃO_............................................................... 37

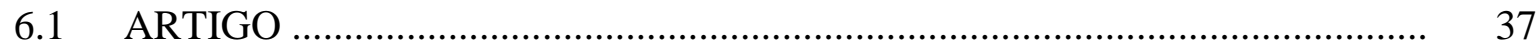

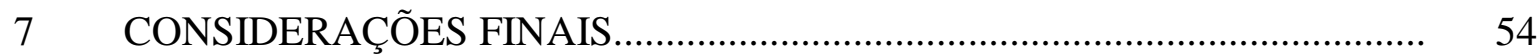

REFERÊNCIAS BIBLIOGRÁFICAS..................................................... 57

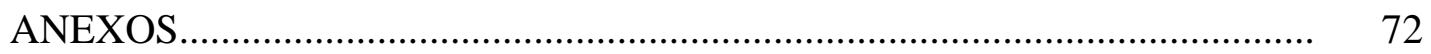




\section{APRESENTAÇÃO}

O presente estudo considera o meu trabalho desenvolvido no Departamento de Assistência Farmacêutica e Insumos Estratégicos (DAF) no Ministério da Saúde (MS), cuja principal atribuição é aquisição de Insulinas NPH e Regular para Atenção Básica do Sistema Único de Saúde (SUS).

Graduado em Farmácia em 2013, iniciei minhas atividades profissionais no âmbito da Assistência Farmacêutica (AF) e desde este momento busquei constante qualificação na área visto a complexidade do trabalho e sua necessidade de aprimoramento constante. Comprometido com esta área da atuação e sensível a situação dos usuários de insulina do Brasil, fui conhecendo e me envolvendo nos projetos e pesquisas que dão sustentabilidade na implementação das políticas públicas na área da $\mathrm{AF}$, o que me possibilitou entender melhor os meandros da gestão do SUS.

Assim, iniciei a função de apoiador da Pesquisa Nacional sobre Acesso, Utilização e Promoção do Uso Racional de Medicamentos (PNAUM). O objetivo principal da pesquisa foi avaliar o acesso, a utilização e o uso racional de remédios por parte da população brasileira, caracterizando as morbidades para as quais os remédios são utilizados.

Conhecer o perfil de utilização de insulinas para o tratamento de diabetes no Brasil é muito importante na definição de projetos/programas voltadas para o setor visto que este tema. Na busca por uma melhor qualificação ingressei no Mestrado Profissional em Saúde Coletiva - Assistência Farmacêutica, ofertada pela Faculdade de Ciências da Saúde da Universidade de Brasília.

Foram objetos de análise os dados resultantes das perguntas relacionadas a Insulina e a Diabetes do bloco de doenças crônicas não transmissíveis do questionário da PNAUM. O fato de ter participado da elaboração e execução da pesquisa, possibilitou-me, a partir dos seus resultados, avaliar se a aquisição e distribuição de insulinas está sendo efetivas.

Considero que este estudo pode ajudar os gestores da área a compreender melhor a prevalência de diabetes, indicação médica e uso de insulina, extratificados por dados sociodemográficos, além de conhecer os tipos de insulinas mais usados no país. O caminho escolhido fornece elementos teóricos que subsidiam meu próprio processo de trabalho e contribuem para o desenvolvimento de ações capazes de subsidiar tomadas de decisões por parte dos gestores do SUS. 


\section{INTRODUÇÃO}

Durante o século passado foram observadas mudanças no perfil epidemiológico populacional que resultaram no processo de transição epidemiológica marcado pelo aumento na prevalência e incidência das Doenças Crônicas Não Transmissíveis (DCNT) (1).

A expansão da Atenção Primária à Saúde (APS), junto a fatores como melhoria da qualidade dos serviços prestados e redução das taxas de tabagismo, foi responsável por uma redução de $20 \%$ das taxas de mortalidade por DCNT na última década, redução resultante de uma política de enfrentamento que culminou no lançamento do Plano de Ações Estratégicas Para o Enfrentamento das DCNT no Brasil - 2011-2022. Esse plano tem como objetivo implementar políticas integradas para prevenção e controle de quatro grupos de doenças, dentre elas a Diabetes Mellitus (DM) (2).

A DM apresenta prevalência mundial estimada em 6,4\% em 2010 considerando a faixa etária de 20 a 79 anos (3). No Brasil, segundo a Pesquisa Nacional de Saúde (PNS) 2013, a prevalência de diabetes é de 6,2\% (IC95\% 5,9-6,6), o que mostra que o diabetes atinge 9 milhões de brasileiros (4).

O tratamento da DM é complexo e um dos seus objetivos centrais é a obtenção de valores glicêmicos o mais próximo da normalidade. Para tal, é essencial que existam meios eficazes o suficiente para que esses valores sejam mantidos em longo prazo (5), podendo o tratamento estar ou não associado à prescrição de medicamentos ou à reposição insulínica. A insulina exógena é utilizada por todos os diabéticos tipo 1, por diabéticos tipo 2 quando a combinação de medicamentos orais associada a medidas não farmacológicas não for mais efetiva e nos casos de diabetes gestacional (6).

Há dois tipos de insulinas: as humanas e as análogas, sendo que o Sistema Único de Saúde (SUS), através da aquisição via Ministério da Saúde (MS), fornece de forma gratuita insulinas humanas através de sua rede assistencial com parte do cuidado e enfrentamento do controle da Diabetes. (7).

Acesso a medicamentos é um dos componentes essenciais da atenção primária à saúde e componente-chave da realização progressiva do direito à saúde e o acesso universal aos cuidados de saúde (8). No que tange ao Sistema Único de Saúde (SUS), a avaliação do real acesso dos usuários às tecnologias de saúde se faz essencial, o que pode ser ratificado na garantia à saúde, que está inserida na Constituição Federal de 1988 sob o dever de assegurar a saúde de forma universal, integral e equânime (9) e a Lei Orgânica da Saúde, que 
institucionalizou o SUS, resultando em profundas mudanças para os serviços de saúde, ao estabelecer a universalidade de acesso, a equidade na prestação de serviços e a integralidade das ações como princípios doutrinários do sistema (10).

Há um interesse nacional em aprimorar o acesso e a utilização de medicamentos, portanto, a Política Nacional de Medicamentos (PNM) regulamenta os aspectos importantes da Assistência Farmacêutica, entre eles, as formas de financiamento e os mecanismos de distribuição de medicamentos por meio da publicação de Leis, Portarias, Decretos, Diretrizes e Programas $(11,12,13,14)$.

A Política Nacional de Assistência Farmacêutica estabelece que a assistência farmacêutica deva se constituir em uma política pública norteadora de outras políticas setoriais, entre as quais se destacam a de medicamentos, de ciências e tecnologias, desenvolvimento industrial e de recursos humanos. A política aponta para a necessidade de uma mudança no então atual cenário da assistência farmacêutica no país, apoiando-se em 13 (treze) eixos estratégicos, voltados para 28 os princípios do SUS de integralidade, universalidade e equidade. Objetiva a melhoria do acesso à população e tem como eixo estratégico a inclusão da assistência farmacêutica nos serviços, o desenvolvimento, valorização, formação, fixação e capacitação de recursos humanos, a descentralização das ações e a articulação em nível regional e estadual dos serviços farmacêuticos, visando à superação da fragmentação de programas desarticulados, bem como a articulação inter setorial para o desenvolvimento científico e garantia de medicamentos de qualidade e seguros (15).

A utilização dos medicamentos é influenciada pelo perfil de morbidade, pela estrutura demográfica, por fatores socioeconômicos, comportamentais e culturais, pelas características do mercado farmacêutico e das políticas governamentais dirigidas ao setor (16). Esse conjunto de fatores precisa ser investigado para permitir a melhor compreensão do papel dos medicamentos no contexto da saúde pública. Dados da PNS 2013 mostram que $80,2 \%$ dos que referiram diagnóstico médico de diabetes estavam em uso de medicamento oral ou insulina para seu tratamento.

Considerando a necessidade de conhecer aspectos relacionados ao acesso, utilização e Uso Racional de medicamentos no Brasil e os objetivos estratégicos estabelecidos no documento "Pesquisas Estratégicas para o Sistema de Saúde” do Ministério da Saúde, quais sejam: "Garantir a assistência farmacêutica no âmbito do Sistema Único de Saúde (SUS)"; "Fortalecer o complexo industrial e de ciência, tecnologia e inovação em saúde como vetor estruturante da agenda nacional de desenvolvimento econômico, social e sustentável, 
melhorando o acesso à saúde e a assistência farmacêutica no âmbito do SUS", foi instituída a Pesquisa Nacional sobre Acesso, Utilização e Promoção do Uso Racional de Medicamentos no Brasil (PNAUM) pela Portaria GM No 2.077, de 17 de setembro de 2012 (17).

Este estudo se justifica por investigar o tema relacionado a utilização de Insulina pelos diabéticos no país, a partir da análise dos resultados da PNAUM e busca contribuir para avaliar a política na qual o insumo está envolvido para, a partir do estudo, reorientar as ações dos gestores envolvidos com a aquisição do citado medicamento. Tendo em vista a problemática apresentada, buscou-se responder as seguintes perguntas: - Qual o perfil demográfico e socioeconômico dos portadores de DM no Brasil? - Como se comporta a indicação médica de insulina e seu uso segundo o perfil demográfico e socioeconômico dos portadores de DM? Quais os tipos de insulinas mais utilizados no Brasil? 


\section{OBJETIVOS}

\subsection{Objetivo Geral}

Descrever a prevalência de diabetes, indicação médica e utilização de insulina pela população adulta brasileira, segundo variáveis sociodemográficas.

\subsection{Objetivos Específicos}

a) Caracterizar o perfil demográfico e socioeconômico dos portadores de Diabetes no Brasil;

b) Descrever a prevalência de indicação médica de insulinas pelos portadores de diabetes;

c) Descrever a prevalência de utilização de insulinas pelos portadores de Diabetes;

d) Descrever os tipos de insulina mais utilizados para controle de Diabetes no Brasil. 


\section{REFERENCIAL TEÓRICO}

\section{1- Diabetes e sua prevalência}

A Diabetes Mellitus (DM) corresponde a um grupo heterogêneo de desordens metabólicas de etiologia múltipla que apresentam em comum o quadro de hiperglicemia crônica associada à falta e/ou à ação ineficiente de insulina. Essa manifestação clínica pode dar margem a um maior risco de complicações micro e macrovasculares que se constituem como principais fatores de risco para Doença Arterial Coronariana (18).

O DM é uma doença em expansão no Brasil e no mundo, configurando-se hoje como uma epidemia mundial. $\mathrm{O}$ envelhecimento da população e as mudanças do modo de vida, com a adoção de hábitos pouco saudáveis como a alimentação inadequada, o sedentarismo e o aumento da obesidade, são os principais fatores responsáveis pelo aumento da incidência e prevalência do diabetes no mundo (19).

Em 2010, estimava-se que 285 milhões de adultos entre 20 e 79 anos eram diabéticos, 6,4\% em termos de prevalência mundial, e a perspectiva é que esse número passe a, aproximadamente, 440 milhões em 2030 (chegando à prevalência mundial de 7,7\%) (3). Estima-se que mais de 25 milhões de pessoas nas Américas Central e do Sul sejam diabéticas, com destaque ao Brasil, que possui pouco mais de 12 milhões de diabéticos (20). De acordo com a Pesquisa PNS 2013, a prevalência autoreferida de diabetes no país é de 6,2\%(4). Dados do inquérito telefônico do Sistema de Vigilância de Fatores de Risco e Proteção para Doenças Crônicas por Inquérito Telefônico - Vigitel - 2013 confirmaram a tendência crescente na prevalência de diabetes, sendo verificado um aumento de $6,3 \%$ em 2011 para $6,9 \%$ em 2013(21).

Essa enfermidade é classificada segundo sua etiologia em quatro tipos: DM tipo 1 (DM 1), DM tipo 2 (DM 2), DM gestacional e outros tipos de DM (22). A primeira corresponde a 5-10\% dos casos e é resultante da destruição das células beta pancreáticas produtoras de insulina, levando a uma deficiência absoluta desse hormônio; DM 2 é a forma mais frequente (90-95\% dos casos) e se caracteriza por defeitos progressivos na secreção e/ou ação da insulina. A DM gestacional é resultante de um processo de intolerância à glicose com início durante o período gestacional. Além desses, há outros tipos de DM, os quais possuem etiologia variada que vão desde endocrinopatias, alterações genéticas e 
infecções à DM decorrente do uso de alguns medicamentos, como os glicocorticóides (23, 24).

Em um estudo realizado por Shaw et al. (3), foram coletados trabalhos em 91 países, publicados entre janeiro de 1989 e março de 2009, para estimar prevalências nacionais de diabetes de 2010 a 2030. Dos 80 países mais populosos do mundo, 47 tinham dados próprios de prevalência nacional de diabetes, baseada em autorelato e/ou medidas glicêmicas. Para os dados nacionais que não dispunham de dados de glicemia, a prevalência foi multiplicada por 1,5 para Canadá e Inglaterra e por 2 para França, Itália, Noruega, Holanda e Eslovênia. Em números absolutos, a Índia foi em 2010 e permanecerá em 2030 como o país com maior número de pessoas com diabetes, seguida da China e dos Estados Unidos, provavelmente devido ao contingente populacional. O Brasil é o quinto, com 7,6 milhões de adultos entre 20 e 79 anos com diabetes. A faixa etária com maior prevalência em 2010 foi de 40 a 59 anos, porém, em 2030 a faixa de 60 a 79 anos ultrapassará esse índice.

\section{2- Mortalidade de diabetes}

A DM se destaca por ser uma das maiores causas de morbimortalidade no adulto, além de acometer indivíduos em todas as idades. É também uma das principais causas de insuficiência renal, amputação de membros inferiores, cegueira e doença cardiovascular. Sua incidência é crescente no mundo e também no Brasil. A Federação Internacional de Diabetes (FID) (25) estima que até 183 milhões (50\%) de pessoas não sabem que têm a doença e que o número de pessoas que vivem com diabetes no mundo aumentará de 366 milhões em 2011 para 552 milhões em 2030, se não forem tomadas medidas urgentes.

O Câncer e o Diabetes correspondem àquelas que não tiveram redução na mortalidade na última década mesmo diante do avanço tecnológico no processo terapêutico e na melhoria do acesso aos serviços de saúde no país. A taxa de mortalidade por DCNT apresentou uma tendência de redução de cerca de 20\% entre 1996 a 2007, sobretudo nas doenças cardiovasculares (31\%) e respiratórias crônicas (38\%), porém, observou-se nesse período um aumento na mortalidade pelo diabetes em $2 \%$ e também no câncer (26). Quando analisado o diabetes como causa associada de morte, esses pesquisadores observaram aumento de $8 \%$ no período de 2000 a 2007. As regiões Norte e Nordeste apresentaram menor declínio na mortalidade por DCNT entre 1996 e 2007, permanecendo com as maiores 
taxas do Brasil, além de terem apresentado aumento na mortalidade por diabetes e outras doenças crônicas nesse período (26).

Segundo Rosa e Schmidt (27), a magnitude das hospitalizações por diabetes na rede pública de saúde brasileira, de 1999 a 2001, é de 327.800 internações da doença como diagnóstico principal. A região sudeste apresentou maior número de óbitos hospitalares por 1.000.000 habitantes, a partir de 20 anos de idade e letalidade hospitalar de 13,3\% em indivíduos com 75 anos ou mais, para o sexo masculino, respectivamente. Essas hospitalizações resultaram em um gasto expressivo por parte do serviço de saúde do estado. Vale ressaltar que, nesse contexto, há impacto dessa situação clínica sobre a mortalidade associada à DM, uma vez que segundo os autores do estudo, os habitantes da região Nordeste apresentaram uma razão de chances duas vezes maior de morrerem durante uma internação por DM como diagnóstico principal em comparação à região Sul (27).

No estudo acima citado, mais de $40 \%$ das hospitalizações estavam relacionadas a complicações crônicas da DM, as quais, por sua vez, refletem de um controle glicêmico inadequado. Um maior número de internações relacionadas à DM esteve significativamente associado à prevalência de controle glicêmico inadequado, resultado semelhante ao encontrado por Shah et al., (28) estudo no qual essa variável se manteve no modelo de regressão final, e por Menzin et al., (29) em estudo retrospectivo envolvendo diabéticos tipo 1 e tipo 2 nos Estados Unidos, que evidenciou que o custo hospitalar relacionado a essas internações era diretamente proporcional ao nível de A1C dos participantes do estudo.

\section{3 - Tratamento medicamentoso para controle da Diabetes}

O tratamento da DM tem como objetivo principal a obtenção de qualidade de vida e longevidade, mantendo os valores glicêmicos e o organismo como um todo em padrões o mais próximo possível da normalidade e, dessa forma, evitar o surgimento de possíveis complicações (30). Para tal, são importantes medidas como o acompanhamento nutricional e realização de atividades físicas orientadas associadas ou não à prescrição de medicamentos orais e/ou à reposição insulínica (24).

A conduta terapêutica para tratamento da DM tipo 2 depende da condição clínica do paciente no primeiro contato com a equipe envolvida, sendo essencial a análise do valor de hemoglobina glicada (A1C) apresentado e de valores da glicemia de jejum (6). Segundo a Associação Americana de Diabetes (ADA) (31) a intervenção no momento do diagnóstico corresponde a modificações de estilo de vida associadas à metformina (antidiabético oral 
anti-hiperglicemiante que reduz a produção hepática de glicose e a resistência à insulina) com aumento da dose e/ou adição de outros antidiabéticos para alcançar e manter os níveis de controle glicêmico.

São encontradas 6 classes de agentes hipoglicemiantes orais: biguanidas, sulfoniluréias, inibidores da alfa-glicosidade, tiazolidinedionas, glinidas e inibidores da DPP-4, com seus respectivos fármacos, sendo que os mais conhecidos são a metformina da classe biguanida e a glibenclamida e glicazida da classe sulfoniluréias. Dentre esses outros antidiabéticos, destaca-se a insulina. (32).

A insulina exógena é utilizada por todos os diabéticos tipo 1 e, segundo a Sociedade Brasileira de Diabetes (SBD) (6), é indicada para diabéticos tipo 2 quando a combinação de medicamentos orais associada a medidas não farmacológicas não for mais efetiva, respeitando a um processo de reposição insulínica progressiva de acordo com os dados da A1C.

De acordo com os dados da PNS 2013 a proporção de pessoas de 18 anos ou mais de idade que referem diagnóstico médico de diabetes e tomaram medicamento para diabetes ou usaram insulina nas duas últimas semanas anteriores à data da pesquisa é de $80,2 \%$ (IC95\% 78-82,5). A região que apresenta maior percentual de utilização é a sudeste 84,6\% (IC95\% $81,1-88,1)$, ao passo que a região norte apresenta o menor percentual $(74,1 \%$; IC95\% 6781,2). (33)

\section{4- Acesso a medicamentos}

O acesso a medicamentos é tema da agenda política internacional. Relacionando-se o consumo de medicamentos com a distribuição geográfica mundial, constata-se uma imensa iniquidade, ou seja, $80 \%$ da produção de medicamentos são consumidos por $18 \%$ da população que vive em países desenvolvidos da América do Norte, da Europa e no Japão. Enquanto o setor farmacêutico movimenta recursos na ordem de mais de 650 bilhões de dólares, a OMS estima que ainda um terço da população mundial não tem acesso regular aos medicamentos $(34,35,36)$.

Segundo Barros (35), enquanto no Brasil há um intensivo processo de medicalização, um grande contingente da população continua à margem do consumo de medicamentos, muitos deles essenciais, o que se dá paralelamente, a um uso de produtos desnecessários.

Dados da Pesquisa Nacional por Amostra de Domicilios (PNAD) e da Pesquisa de Orçamentos familiares (POF) 2008-2009 indicam que os programas de assistência 
farmacêutica do SUS são a única forma de acesso a medicamentos para grande parcela da população brasileira, principalmente aquela de menor renda (37).

Nas metas para o desenvolvimento do milênio, verifica-se uma preocupação em assegurar o acesso a medicamentos essenciais, tendo em vista a constatação de que em 1999 aproximadamente $80 \%$ da população mundial sem acesso aos medicamentos essenciais moravam em países de baixa renda. O grupo formado para trabalhar as questões referentes ao acesso a medicamentos essenciais considerou os indicadores de acesso propostos pela OMS, ou seja: a proporção da população com acesso aos medicamentos essenciais é a percentagem da população que tem acesso a, no mínimo, 20 itens dos medicamentos essenciais (38).

Os sistemas universais de saúde se deparam, em maior ou menor grau, com a dificuldade de garantir a toda população os medicamentos de que necessita. Portanto, buscase identificar os principais fatores que dificultam o acesso aos medicamentos, bem como as experiências exitosas de outros países para superar os obstáculos relacionados ao mesmo. Merece destaque, a Política de Assistência Farmacêutica adotada na Europa, em especial na Inglaterra, na França e na Alemanha, que tem implementado políticas para contenção de despesas, regulamentação dos preços dos medicamentos e melhoria do acesso aos medicamentos seguros e eficazes. A Inglaterra e Holanda implantaram a "clinical governance", que é o gerenciamento, entre outros, da prescrição de medicamentos, para tentar reduzir os erros nas prescrições e promover a prescrição racional (39).

Revisão sobre acesso e uso de medicamentos realizado no México, no período de 1990 a 2004, incluiu 2.289 artigos e destes identificou 108 como relevantes para a Política de Assistência Farmacêutica por abordarem: prescrição inadequada, automedicação, iniquidade no acesso e desabastecimento de medicamentos nos serviços públicos de saúde. Dos 13 artigos relativos a acesso, apenas 04 artigos relacionava o acesso a medicamentos anti-hipertensivos e 01 artigo a antidiabéticos (40).

No Brasil, o acesso a medicamentos é garantido constitucionalmente. A Lei $\mathrm{n}^{\circ}$ 8.080/90, estabeleceu que o acesso à saúde é direito de todo cidadão e papel do Estado prover a "assistência terapêutica integral", assegurando a distribuição universal e gratuita de medicamentos no setor público (41).

Em 1998, após a extinção da Central de Medicamentos (CEME), foi regulamentada a Política Nacional de Medicamentos (PNM), através da Portaria n ${ }^{\circ}$ 3.916/98. A PNM tem como objetivo precípuo garantir a necessária segurança, eficácia e qualidade dos 
medicamentos, a promoção do uso racional e o acesso da população àqueles considerados essenciais $(15,33,41,42)$.

O Decreto $\mathrm{n}^{\circ} 7.508 / 11$ de 28 de junho de 2011 (43) que regulamenta a Lei $\mathrm{n}^{\circ}$ 8.080/90, para dispor sobre a organização do SUS, o planejamento da saúde, a assistência à saúde e a articulação interfederativa, dispõe em seu artigo 28:

O acesso universal e igualitário à assistência farmacêutica pressupõe, cumulativamente:

I- estar o usuário assistido por ações e serviços do SUS;

II- ter o medicamento sido prescrito por profissional de saúde, no exercício regular de suas funções no SUS;

III- estar a prescrição em conformidade com a RENAME e os Protocolos Clínicos e

Diretrizes Terapêuticas ou com a relação específica complementar estadual, distrital ou municipal de medicamentos; e

IV- ter a dispensação ocorrido em unidades indicadas pela direção do SUS.

Cabe ao Estado a formulação e implementação de ações que assegurem o acesso da população aos serviços de promoção, proteção e recuperação da saúde. No caso da Assistência Farmacêutica (AF), esse acesso é dificultado pela escassez de recursos para atender às demandas sempre crescentes (44).

Por outro lado, Santos-Pinto (44) afirma que a AF só se concretiza mediante o acesso aos medicamentos pelos pacientes, nas quantidades adequadas e no momento necessário. Em vista disso, o Estado gestor se orienta para a provisão de medicamentos considerados essenciais ou que combatam as doenças de grande impacto para a saúde pública.

A Política de AF em qualquer âmbito deve considerar os critérios de eficácia (medicamentos com eficácia clínica comprovada), efetividade (relacionada aos aspectos que vão desde a prescrição até a acessibilidade ao medicamento) e eficiência (assegurar os medicamentos dispondo o mínimo de recurso possível) (37).

No Brasil, mesmo com a adesão dos municípios ao Plano de Reorganização da Atenção à Hipertensão Arterial e ao Diabetes Mellitus e incentivo à Política Nacional de Assistência Farmacêutica para hipertensos e diabéticos, estudos mostram a dificuldade dos hipertensos e diabéticos em controlar a sua pressão arterial e a glicemia, respectivamente (45).

Os medicamentos de uso contínuo assumem grande importância no tratamento de doenças crônico-degenerativas, como a Hipertensão Arterial e o Diabetes. Estudos demonstram que a falta de acesso ao tratamento ou o seu uso incorreto são causas frequentes de retorno de pacientes aos serviços de saúde ou hospitalizações (46). Considerando-se que 
a maioria da população atendida no serviço público de saúde é de baixa renda, a obtenção gratuita é, frequentemente, a única alternativa para favorecer a adesão ao tratamento. Os medicamentos, por sua vez, representam parte importante dos gastos dos serviços de saúde, portanto é imprescindível ações em prol do seu uso racional.

Outro aspecto fundamental para assegurar a qualificação do acesso a medicamentos é a estruturação da Assistência Farmacêutica no Sistema Único de Saúde. Nesse sentido, em janeiro de 2008, o MS, o Conselho Nacional de Secretários de Saúde (CONASS) e o Conselho Nacional de Secretarias Municipais de Saúde (CONASEMS) assinaram Nota Técnica Conjunta, que trata da qualificação da Assistência Farmacêutica. O documento ressalta que:

O acesso no contexto do uso racional e seguro não pode estar restrito ao produto medicamento, mas também, por meio de articulação das ações inseridas na Assistência Farmacêutica e envolvendo, ao mesmo tempo, o acesso a todo o conjunto de ações de atenção à saúde (47).

\section{5 - Programas e Políticas de acesso ao tratamento da Diabetes no Brasil}

Há dois tipos de insulinas no Brasil: as insulinas humanas (em monoterapia ou em pré-mistura) e as análogas (em monoterapia ou bifásicas) (7). A classificação das insulinas se dá pelo tempo de ação das mesmas com base no tipo de preparação. Nesse contexto, temse a insulinas humanas de ação curta (regular), intermediária (NPH - Neutral Protamine Hagedorn) e basal, sendo as duas últimas originadas a partir da primeira (48). Modificações na cadeia de aminoácidos das insulinas humanas resultaram no desenvolvimento das chamadas insulinas análogas, as quais possuem diferenças farmacocinéticas importantes especialmente em relação ao tempo e início de ação (49). Dentre as insulinas análogas estão as insulinas lispro e aspart, análogos de ação rápida, e glargina e detemir, análogos de ação longa.

O Ministério da Saúde publicou em dezembro de 2010 uma revisão sistemática, por meio do Boletim Brasileiro de Avaliação de Tecnologias em Saúde (50), comparando a eficácia das insulinas detemir e glargina com a NPH em relação ao controle glicêmico e à ocorrência de episódios de hipoglicemia em adultos, crianças e adolescentes (DM 1). Os resultados demonstraram eficácia similar em termos de capacidade de redução da hemoglobina glicada (A1C). Entretanto, segundo este mesmo estudo, os análogos apresentariam vantagens em relação à NPH relacionadas ao perfil de segurança, obtendo-se 
melhores efeitos noturnos, resultando em níveis mais baixos de glicemia de jejum e num menor número de episódios de hipoglicemia noturna. Entretanto, este boletim aponta que "os vieses identificados nos estudos podem comprometer a validade desses achados" e conclui que "as evidências clínicas disponíveis não suportam a superioridade clínica das insulinas análogas em relação à NPH, e como os custos associados às primeiras são superiores, os recursos financeiros devem ser direcionados para a estruturação de programas que visem a maximização dos benefícios do tratamento atualmente disponível no SUS para o controle da DM1".

Quanto às insulinas de ação rápida, um estudo de revisão sistemática de ensaios clínicos controlados randomizados (51) informa que o uso de insulinas análogas à humana de curta duração (asparte e lispro) no tratamento do DM, aponta, com grau de recomendação "A", que "a melhor evidência científica disponível sugere que as insulinas lispro e asparte, análogas à humana, apresentam um leve benefício clínico em relação à insulina humana regular em adultos com DM 1 para diminuir a ocorrência dos eventos de hipoglicemia noturna". Entretanto, entre outros aspectos, esse estudo apontou que os dados se demonstraram insuficientes para definir a superioridade das insulinas asparte e lispro em relação à insulina regular na redução dos níveis de A1C. Diante do contexto encontrado, concluiu pela não recomendação da incorporação dessas análogas no rol dos medicamentos distribuídos pelo SUS.

A análise dos estudos publicados no que se refere à comparação entre as duas apresentações de insulinas no país permite a conclusão de que as evidências são ainda insuficientes para a definição da efetividade das insulinas análogas, especialmente considerando que alguns deles possuem desenhos experimentais discutíveis não considerando aspectos como orientação quanto à utilização das insulinas e armazenamento, acompanhamento nutricional e realização de atividades físicas (52).

O MS concluiu um estudo que objetivou foi avaliar as insulinas análogas lentas e rápidas no tratamento do diabetes do tipo 1, em comparação às insulinas NPH e Regular, quanto aos parâmetros de eficácia, segurança, custo-efetividade e impacto orçamentário para o SUS. Os estudos identificados na busca, bem como as meta-análises realizadas a partir dos desfechos de interesse sugerem que não é possível atestar inferioridade, similaridade ou superioridade entre as insulinas análogas de ação longa e rápida em relação aos seus comparadores convencionais (insulina humana recombinante NPH e regular), respectivamente. Assim, Os membros da CONITEC, por unanimidade, deliberaram como recomendação final a não incorporação das insulinas análogas de curta ação (aspart, lispro e 
glulisina) e de longa ação (detemir e glargina) para o tratamento do Diabetes Mellitus tipo I. (53).

Devido à sua natureza crônica, aos meios necessários para o seu controle e tratamento adequados e à gravidade de possíveis complicações associadas, a DM constituise em uma doença onerosa: a Federação Internacional de Diabetes em 2009 estimou que, no ano seguinte, essa enfermidade seria responsável por 11,6\% do total de gastos com saúde, chegando ao custo de 376 bilhões de dólares (54).

Dentre esses medicamentos estão as insulinas humanas NPH e regular, as quais possuem valor terapêutico e segurança comprovados com base em evidências clínicas, além de baixo custo associado (7).

O custo mensal do tratamento com a insulina detemir e com a insulina glargina é cerca de 6 e 10 vezes maior do que o custo associado ao tratamento com a insulina NPH, respectivamente; já o tratamento com a insulina lispro, por sua vez, é quase três vezes maior do que o que envolve a insulina regular (55). Tais aspectos requerem uma análise criteriosa para a incorporação dessa tecnologia no SUS já que, conforme a Secretaria de Atenção à Saúde do MS, as insulinas análogas apresentam vantagens marginais em comparação às insulinas humanas e, devido ao seu alto custo, sua relação custo-efetividade é questionável (56).

Em 2002, foi instituído, através da Portaria n 371/GM, o Programa Nacional de Assistência Farmacêutica para Hipertensão Arterial e Diabetes Mellitus, parte integrante do Plano Nacional de Reorganização da Atenção a Hipertensão Arterial e Diabetes Mellitus (11), com os seguintes objetivos:

a) implantar o cadastramento dos portadores de hipertensão e diabetes mediante a instituição do Cadastro Nacional de Portadores de Hipertensão e Diabetes a ser proposto pela Secretaria de Políticas de Saúde do Ministério da Saúde e pactuado na Comissão Intergestores Tripartite - CIT;

b) ofertar de maneira contínua para a rede básica de saúde os medicamentos para hipertensão e diabetes definidos e propostos pelo Ministério da Saúde, validados e pactuados pelo Comitê do Plano Nacional de Reorganização da Atenção à Hipertensão Arterial e Diabetes e pela CIT (11).

O Plano fortalece a concepção de que a identificação precoce dos casos e o estabelecimento do vínculo entre os portadores e as unidades da Estratégia Saúde da Família são elementos imprescindíveis para o sucesso do controle desses agravos. 
A Assistência Farmacêutica se constitui em importante componente integrante do SUS, segundo Arrais (16), sendo fundamental para efetiva implementação das ações de promoção e melhoria das condições da assistência à saúde da população.

O acesso a medicamentos, entendido como bem de saúde, é garantido constitucionalmente em nosso país. A PNM brasileira em vigor foi institucionalizada através da Portaria 3916 e tem como objetivo precípuo — garantir a necessária segurança, eficácia e qualidade dos medicamentos, a promoção do uso racional e o acesso da população àqueles considerados essenciais $(16,33,41,57)$.

Para alguns autores, o acesso implica a garantia de ingresso do indivíduo no sistema de saúde e/ou o uso de bens e serviços considerados socialmente importantes, sem obstáculos físicos, financeiros ou de outra natureza $(58,59)$.

Desde a implantação da PNM, foi estabelecida a reorientação da Assistência Farmacêutica, direcionada para o seu intensivo processo de descentralização. Esta nova lógica estabeleceu a responsabilidade dos três níveis de gestão, tanto no que se refere ao financiamento, como ao estabelecimento de políticas em prol da promoção do acesso e uso racional de medicamentos $(57,60)$.

A PNAF é conduzida pelo Departamento de Assistência Farmacêutica e Insumos Estratégicos - DAF. Do ponto de vista operacional, conforme normas da portaria GM/MS n. 204, de 29 de janeiro de 2007, que regulamentou a transferência dos recursos financeiros federais, na forma de blocos de financiamento, o bloco de financiamento da Assistência Farmacêutica (61), é constituído por três componentes regulamentados por portarias específicas:

- Componente estratégico: destina-se a garantia do tratamento de doenças de perfil endêmico, cujo controle e tratamento possuem protocolos, normas estabelecidas e impacto sócio-econômico;

- Componente especializado: é uma estratégia de acesso a medicamentos no âmbito do Sistema Único de Saúde, onde sua principal característica é a busca da garantia da integralidade do tratamento medicamentoso, em nível ambulatorial, cujas linhas de cuidado encontram-se definidas em Protocolos Clínicos e Diretrizes Terapêuticas (PCDT), publicados pelo Ministério da Saúde (62). 
- Componente básico: destina-se à garantia de acesso aos medicamentos para tratamento dos agravos mais prevalentes e prioritários no âmbito da atenção básica (63).

Dessa forma, os medicamentos e insumos para o tratamento do DM encontram-se no componente básico da assistência farmacêutica, uma vez que a centralidade do cuidado desta doença crônica se dá no âmbito da atenção básica em saúde. Os medicamentos e insumos disponibilizados pelo SUS aos portadores de diabetes foram estabelecidos em 2007, por meio da Portaria do Ministério da Saúde no 2. 583, de 10 de outubro de 2007, em cumprimento à Lei 11. 347, de 10 de outubro de 2006 e encontram-se destacados abaixo (14):

- Antidiabéticos injetáveis: Insulina Humana NPH e Regular;

- Antidiabéticos orais: Glibenclamida, Glicazida e Cloridrato de Metformina;

- Insumos: seringas com agulha acoplada para aplicação de insulina, lancetas e tiras reativas para o exame de ponta de dedo.

Em 2013 foi pactuado o financiamento de medicamentos entre as três esferas de governo, sendo os valores mínimos repassados pela União de $\mathrm{R} \$ 5,10$ por habitante/ ano e as contrapartidas dos Estados e Municípios equivalem a $\mathrm{R} \$ 2,36$ por habitante/ano, com previsão de revisão de valores(14).

Visando ampliar o acesso a medicamentos não só para os usuários do SUS, como para um maior contingente populacional, implantou-se a Lei de medicamentos genéricos e o programa Farmácia Popular do Brasil $(57,63)$.

A implantação da Lei de medicamentos genéricos no Brasil buscou, dentre outras alternativas, reduzir o incremento exagerado nos preços dos medicamentos $(35,57)$.

As insulinas NPH e Regular são adquiridas centralizadamente pelo Ministério da Saúde e fornecidas aos governos estaduais, a quem compete distribuí-las aos municípios, de acordo com suas necessidades (14). Além da disponibilidade desses medicamentos na rede pública, o portador de DM também os obtém sem custo, nas farmácias da rede própria ou naquelas credenciadas ao Programa Farmácia Popular do Brasil. As farmácias da rede própria referem-se às implantadas pelo governo federal a partir de 2004, em parcerias com estados, o Distrito Federal, municípios e hospitais filantrópicos. As credenciadas são farmácias e drogarias privadas habilitadas pelo governo federal a disponibilizar gratuitamente os medicamentos antidiabéticos, anti-hipertensivos e antiasmáticos à 
população, e outros medicamentos, mediante co-pagamento, identificadas pela marca do programa “Aqui tem Farmácia Popular". Este programa foi iniciado por meio da rede própria em 2004 (63), e ampliado à rede credenciada em 2006 (64), na forma de copagamento, segundo informação no portal do Ministério da Saúde, é considerado pelo governo federal, como uma estratégia de ampliação de acesso aos medicamentos, em razão da capilaridade da rede privada, sem a pretensão de substituir o fornecimento dos medicamentos da atenção básica pela rede pública de saúde (65). Destaca-se, ainda, o lançamento da Campanha "Saúde não tem preço" (SNTP), com o objetivo de disponibilizar, gratuitamente, medicamentos indicados para o tratamento de hipertensão e diabetes nas farmácias e drogarias credenciadas por meio do "Programa Aqui Tem Farmácia Popular", que constituiu mais um aspecto favorável a universalização do acesso e utilização de medicamentos para hipertensos e diabéticos (66).

Dos medicamentos definidos pelo SUS para o tratamento do diabetes, a glicazida não é fornecida pelo Farmácia Popular. Já as insulinas NPH e Regular disponibilizadas pela rede pública apenas em frascos de $10 \mathrm{ml}$, são ofertadas por esse programa também em frascos de $5 \mathrm{ml}$, além de outras apresentações, para uso em canetas de aplicação (carpule/refis de 1,5 e $3 \mathrm{ml}$ ) (67).

Adicionalmente, os medicamentos para o DM são também oferecidos pelo comércio farmacêutico.

Dados do ministério da Saúde revelam que o acesso a medicamentos para hipertensão, diabetes e asma aumentou até 343\% nos últimos anos com o SNTP e que uma das consequências disso foi a estabilização do número de internações por complicações decorrentes do diabetes desde 2010. Entretanto, vários autores (60, 69,70 e 71) identificaram disparidades e deficiências no acesso a medicamentos pela população.

O Plano de Ações Estratégicas Para o Enfrentamento das DCNT no Brasil, 20112022, foi lançado com o objetivo de preparar o país nos próximos dez anos para enfrentar e deter estas doenças $(44,72)$.

Apesar dos investimentos na assistência farmacêutica, (44) relatam que a compra direta pelos indivíduos representa ainda uma das principais formas de acesso aos medicamentos, situação que se torna mais grave no caso de doenças crônicas que demandam medicamentos de uso contínuo, muitas vezes com tratamento perdurando por toda a vida do paciente. Assim, devido aos altos custos dos medicamentos e tratamentos, estes podem se tornar inacessíveis para considerável parte da população. 
O controle rigoroso da hipertensão arterial e da glicemia são capazes de reduzir as complicações tanto do diabetes quanto da hipertensão arterial. Portanto, é necessário investimento, monitoramento e uma abordagem ampla ao lidar com esse grupo de usuários, garantindo tanto a intervenção medicamentosa, como não medicamentosa acompanhada de mudança no estilo de vida (73).

\section{6- Monitoramento das DCNT}

O MS cumpre a tarefa de monitorar os principais determinantes das DCNT no Brasil através da Pesquisa por Inquérito Telefônico de Vigilância Epidemiológica - VIGITEL, cujo objetivo é monitorar a frequência e a distribuição dos principais determinantes das DCNT por inquérito telefônico. Assim, o VIGITEL vem contribuindo na formulação de políticas públicas que promovam a melhoria da qualidade de vida da população brasileira. Os resultados da referida pesquisa embasaram a elaboração do Plano de Ações Estratégicas para o Enfrentamento das Doenças Crônicas no Brasil 2011-2022, bem como subsidiam o monitoramento das metas propostas (74).

O VIGITEL não pode aferir diretamente a frequência de fatores de risco para doenças crônicas que necessitem de diagnostico médico por ser realizado a partir de entrevistas telefônicas. Neste sentido, de forma semelhante à empregada por outros sistemas de vigilância, aquela Pesquisa estima a frequência de indivíduos que referem diagnóstico médico prévio do fator de risco. É evidente que as frequências assim estimadas são influenciadas pela cobertura da assistência a saúde existente em cada cidade, podendo, assim, subestimar, em maior ou menor grau, a prevalência real do fator de risco na população. De qualquer modo, tem-se a obtenção de informações úteis visando avaliar a demanda por cuidados de saúde originada pela presença do fator (74).

Com a publicação e a divulgação dos dados dos suplementos-saúde da PNAD, ampliou-se o conhecimento sobre as características de saúde da população brasileira, constituindo um conjunto de informações de abrangência nacional de grande relevância para subsidiar a formulação, o monitoramento e a avaliação das políticas públicas de saúde (75, 76 e 77). A Pesquisa Nacional de Saúde (PNS), por ser uma pesquisa independente da PNAD, mas integrante do Sistema Integrado de Pesquisas Domiciliares (SIPD), se beneficiou da Amostra Mestra da PNAD contínua (78), com maior espalhamento geográfico e ganho de precisão das estimativas. Com desenho próprio, elaborado, especificamente, para 
coletar informações de saúde, a PNS foi planejada para a estimação de vários indicadores com a precisão desejada e para assegurar a continuidade no monitoramento da grande maioria dos indicadores do Suplemento Saúde da PNAD.

As informações da PNS serão utilizadas para subsidiar a formulação das políticas públicas nas áreas de promoção, vigilância e atenção à saúde do SUS, alinhadas às estratégias do Plano de Ações Estratégicas para o Enfrentamento das Doenças Crônicas Não Transmissíveis, no Brasil, no período 2011-2022 (79, 80). Por meio da PNS será possível monitorar as metas de redução de DCNT pactuadas com a Organização Mundial da Saúde (OMS) (81), como o tratamento de hipertensos e diabéticos, a redução do consumo do sal, do tabaco, do álcool e da inatividade física, deter o crescimento da obesidade, dentre outras.

Não existiam, no país, estudos de base populacional nos moldes dos inquéritos domiciliares, com representatividade além da escala municipal ou regional, devido aos vultosos recursos financeiros demandados, à exigência de recursos humanos altamente qualificados e às dificuldades operacionais relacionadas com o trabalho de campo em uma investigação desse porte. A PNAUM constitui a primeira investigação de abrangência nacional, realizada no país, a respeito da questão do acesso a medicamentos e do uso racional do medicamento (82).

Os inquéritos de saúde, incluindo os inquéritos sobre medicamentos, representam uma estratégia fundamental para a compreensão das disparidades existentes no acesso a medicamentos, seja entre Grandes Regiões do país, seja entre diferentes segmentos da população brasileira. Tais estudos possibilitam monitorar os padrões e tendências de acesso e fontes de obtenção de medicamentos, de forma a redirecionar as políticas públicas farmacêuticas e favorecer ações de saúde e de assistência farmacêutica mais equânime no país (83).

A realização de estudos sobre utilização, acesso e uso racional de medicamentos, em escala nacional, representa uma forma de proporcionar subsídios relevantes às autoridades governamentais e sanitárias brasileiras, de modo que sejam avaliadas as políticas de Assistência Farmacêutica, os investimentos na seleção e na aquisição de medicamentos e o controle dos gastos, a fim de efetivar melhorias nas políticas públicas de saúde e Assistência Farmacêutica e nas condições de saúde e qualidade de vida da população brasileira (82). 


\section{MÉTODOS}

\section{Delineamento da Pesquisa}

Delineamento transversal, através de inquérito de base populacional com amostra representativa da população brasileira segundo Censo, IBGE 2010.

\section{População de estudo}

Residentes em domicílios particulares permanentes na zona urbana do território brasileiro. A população rural não foi contemplada no estudo, em razão da dificuldade adicional que essa população imporia ao projeto, implicando elevado aumento de custos, além do fato de que na data do início da pesquisa (2013), mais de $80 \%$ da população brasileira residia em áreas urbanas.

\subsection{Coleta de Dados}

Os entrevistadores armazenavam os dados coletados em um dispositivo eletrônico, tablet, equipado com conexão $3 \mathrm{G}$ de acesso à internet e GPS, transmitidos para os servidores da empresa a cada sincronização. A sincronização poderia ser feita ao final de cada entrevista ou em outro momento, caso não houvesse conexão no local ou hora da entrevista. Os mesmos equipamentos também foram utilizados para a comunicação dos membros de cada equipe entre si ou com a sala de situação, que lhes prestava suporte quanto às dúvidas de manejo do software e de preenchimento dos questionários.

Os profissionais que conduziram a coleta receberam treinamento administrado pela empresa, com a participação dos pesquisadores da equipe responsável pelo estudo.

O primeiro módulo do aplicativo continha a lista de endereços selecionados para cada um dos setores censitários, como também a orientação quanto aos grupos etários elegíveis em cada domicílio.

Os instrumentos de coleta de dados da pesquisa PNAUM componente Inquérito foram estruturados em blocos, de modo a propiciar a coleta das variáveis de interesse. Os blocos foram aplicados de forma diferente para três grupos. O primeiro grupo, identificado como "Adultos", foi aplicado às pessoas com 15 anos ou mais. O segundo grupo, "Incapazes de se comunicar", incluiu as pessoas sem capacidade de se comunicar ou de prestar 
informações sobre si devido a doença física ou mental, privação da fala ou falta de discernimento para responder às questões, e o terceiro grupo, "Crianças" inclui crianças e jovens de 0 a 15 anos de idade. Para os dois últimos grupos, alguns blocos não foram aplicados ou sofreram adaptações.

O instrumento de pesquisa (Anexo 01) continha onze blocos de conteúdo e duas fichas de detalhamento de medicamentos:

- Informações gerais do entrevistado

- Doenças crônicas (não transmissíveis)

- Detalhamento dos medicamentos de uso contínuo

- Uso de serviços de saúde

- Doenças agudas

- Detalhamento dos medicamentos de uso eventual

- Contraceptivos

- Serviços de farmácia

- Comportamentos que podem afetar o uso de medicamentos

- Bulas e embalagens

- Estilo de vida

- $\quad$ Plano de saúde

- Informações do domicílio

O fluxo da entrevista para os entrevistados Adultos está apresentado na Figura 1. 
Figura 1: Fluxo de blocos respondidos pelos Adultos

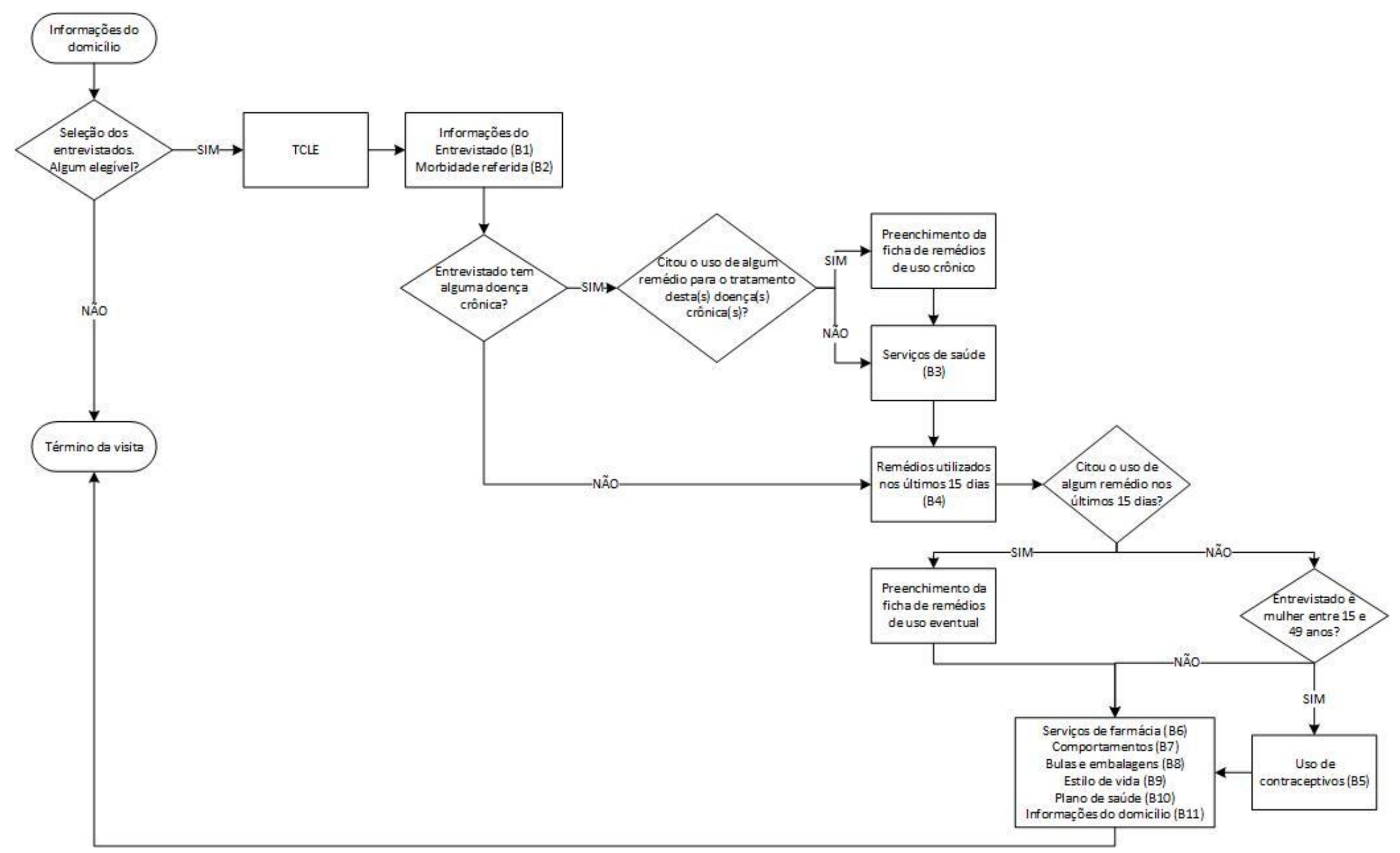

Fonte: Caderno 01 PNAUM, 2014, p. 20 (em publicação). 
No bloco 02 do instrumento foram levantadas informações sobre as doenças crônicas, dentre elas o Diabetes, em que foi investigado um conjunto de questões específicas, referentes ao diagnóstico, indicação médica para tratamento e uso de medicamentos bem como o controle e limitações causadas pela doença.

O entrevistado também foi questionado quanto ao atendimento em emergências e internações. Considerou-se qualquer atendimento ou internação, sejam estes em decorrência das doenças crônicas citadas ou não.

Caso o entrevistado tivesse alguma doença crônica e, tivesse relatado o uso de algum medicamento para seu tratamento, era realizado o preenchimento da ficha de detalhamento de medicamentos de uso contínuo ou crônico, uma para cada medicamento citado.

Foi utilizada uma ficha de medicamento de uso contínuo e eventual para realizar o preenchimento das informações dos medicamentos referidos, conforme os medicamentos utilizados pelo entrevistado. Vale salientar que para fazer o registro dos nomes dos medicamentos, foi dado preferência para a observação da embalagem, quando existente.

Para o preenchimento dos dados sobre os medicamentos referidos, foi solicitado ao entrevistado que mostrasse todos os remédios em uso. Foi considerado remédio qualquer tipo de produto utilizado para curar ou aliviar doenças, sintomas, desconforto ou mal-estar. Dessa forma, um remédio poderia ser tanto um medicamento manipulado ou industrializado, quanto um chá, produtos homeopáticos e plantas medicinais, por exemplo.

Outro dado utilizado foi extraído do bloco 10 que questionou o entrevistado quanto ao seu plano de saúde médico e os itens cobertos pelo plano, com interesse na cobertura de medicamentos.

Para auxiliar na caracterização socioeconômica foram coletadas informações referentes ao domicílio, como bens móveis, renda familiar e número de cômodos, necessárias para operacionalizar o Critério de Classificação Econômica Brasil (CCEB) da Associação Brasileira das Empresas de Pesquisa (ABEP). Numa segunda seção foram coletadas as informações sócio demográficas da pessoa de referência na família. Caso o entrevistado não conseguisse apontar claramente quem é, optou-se por indicar a pessoa de maior renda ou de maior idade.

As informações dos moradores adultos, incapazes de se comunicar por quaisquer motivos, foram obtidas também por meio do informante substituto. A versão do instrumento de coleta utilizada nestes casos foi a mesma dos demais moradores adultos, não tendo sido aplicados os blocos Comportamentos que podem afetar o uso de medicamentos, Bulas e embalagens e Estilo de vida. 


\subsection{Amostra e amostragem}

As informações preliminares, utilizadas para elaborar a estimativa do tamanho da amostra, foram obtidas a partir da análise dos dados de acesso aos medicamentos, publicada na Pesquisa Nacional por Amostra de Domicílios - PNAD de 2008, do IBGE. Os resultados dessa análise mostravam que, no país, dentre aqueles que tinham alguma doença e utilizavam medicamentos de uso contínuo, o acesso completamente gratuito a todos os medicamentos era da ordem de $34 \%$, e o acesso completamente pago a tais medicamentos era de 44\%. Do total de usuários de medicamentos, $10 \%$ obtinha parte de seus medicamentos gratuitamente, e parte dessa população obtinha esses medicamentos por meio de pagamento. Os dados da PNAD 2008 indicavam que a falta de acesso total ou parcial, da população brasileira que tinha alguma doença e utilizava medicamentos de uso contínuo, ocorreu em $12 \%$ dos casos. Por dedução, o acesso total aos medicamentos de uso contínuo, gratuito ou com pagamento, foi de $88 \%$ entre os que tinham alguma doença e utilizavam medicamentos de uso contínuo.

Para o estudo, foram definidos quarenta domínios, baseados em oito domínios demográficos, nas cinco Grandes Regiões brasileiras. Tendo em vista os objetivos do estudo, os grupos demográficos foram definidos segundo faixa etária e sexo de forma a permitir estimativas precisas para diferentes subgrupos da população. Desta forma, alguns grupos etários foram divididos por sexo, e outros, não. Os oito grupos estão descritos na Tabela 1.

Quadro 1 - Domínios regionais e demográficos da amostra.

\begin{tabular}{lll}
\hline \multicolumn{1}{c}{ Domínio } & \multicolumn{1}{c}{ Idade } & \multicolumn{1}{c}{ Sexo } \\
\hline 1 & 0 a 4 anos & Sem distinção \\
2 & 5 a 19 anos & Sem distinção \\
3 e 4 & 20 a 39 anos & Homens e mulheres \\
5 e 6 & 40 a 59 anos & Homens e mulheres \\
7 e 8 & 60 anos ou mais & Homens e mulheres \\
\hline
\end{tabular}

Fonte: Caderno 01 PNAUM, 2014, p. 15 (em publicação).

O plano de amostragem teve como objetivo a produção de amostras probabilísticas específicas a cada um dos 40 domínios definidos anteriormente. Critérios de precisão, número de entrevistas e 
métodos para obtenção das amostras foram propostos para aplicação separada em cada um desses domínios.

O critério de precisão adotado fixa o valor máximo de 0,05 para qualquer coeficiente de variação de estimativas de proporção. Ou seja, o erro padrão de qualquer estimativa alcançada na pesquisa será proporcional ao seu valor pontual, e não superior a 0,05 multiplicado pelo valor de $p$.

Com o intuito de maximizar a precisão das estimativas, foram sorteadas 960 entrevistas em cada um dos 40 domínios do estudo. No total, o projeto deveria realizar, no mínimo, 38.400 entrevistas, definidas pelo produto das 960 entrevistas pelos quarenta domínios.

O primeiro estágio do processo de amostragem teve início com o sorteio da unidade primária de amostragem - UPA. Para isso, foi utilizado o cadastro de municípios, contendo o total de domicílios particulares permanentes por Grande Região, extraído do banco de dados SIDRA (Sistema IBGE de Recuperação Automática) do Instituto Brasileiro de Geografia e Estatística (IBGE). Os municípios de maior porte, em geral as capitais, com o número total de domicílios superior ao intervalo de sorteio (total de domicílios no município dividido por 60), foram divididos em, no máximo, 11 UPAS (total de domicílios no município dividido por intervalo de sorteio). Nesses casos, cada UPA foi incluída na amostra com probabilidade igual a 1.

No momento do sorteio, dentro de cada Grande Região, as UPAS foram ordenadas pelo total de domicílios, na ordem crescente por Unidade da Federação. O procedimento de sorteio da UPA foi realizado pelo método de probabilidade proporcional ao número de domicílios. Foram sorteadas, no total, 60 UPAS em cada região, menos o número de UPAS com probabilidade igual a 1.

No segundo estágio, foram utilizados os dados agregados por setor censitário, segundo os dados do Censo de 2010 do IBGE (IBGE, 2010). Nessa etapa, foram observadas as seguintes particularidades:

a) Não houve sorteio de setores nas UPAS sorteadas com menos de 4 setores censitários urbanos. Nesses casos, os setores de municípios próximos ficaram como reservas.

b) Nas capitais, as UPAS foram compostas por grupos de subdistritos e, dentro de cada UPA, foram sorteados 2 setores censitários. Por exemplo, Manaus tem 7 UPAS e, no arquivo de agregados de setores, esses setores censitários estão agrupados em 10 subdistritos, ou seja, nesse caso, temos a razão de 1,4 distritos por UPA (10/7). Nesse exemplo, as 3 primeiras UPAS têm 2 subdistritos e, as demais, 1 único subdistrito.

c) Nas demais UPAS foram sorteados 2 setores censitários urbanos, no segundo estágio. 
d) Após o sorteio dos setores, estes foram cruzados com o arquivo do IBGE, a fim de identificar os setores classificados como Favela.

No sorteio do terceiro estágio, relativo a domicílios, foi utilizado o Cadastro Nacional de Endereços do Censo 2010 para fins de pesquisa, fornecido pelo IBGE. Os setores sorteados foram divididos em três grupos. O primeiro foi composto pelos setores atualizados, cuja cobertura de endereços válidos no cadastro é de, no mínimo, 90\%. O segundo grupo era composto por setores com cobertura inferior a 90\%; e o terceiro grupo foi formado por setores classificados como Favela.

As amostras de endereços foram obtidas por amostragem sistemática, considerando a ordem dos endereços no arquivo. Os setores sorteados que contavam com menos de 100 domicílios foram agrupados com o setor vizinho. Os setores não atualizados e de Favela tiveram os seus endereços atualizados na etapa imediatamente anterior à realização das entrevistas naquele município.

Ao final do trabalho de campo, em cada UPA, foi calculada a taxa real de resposta (TRR = número de não respondentes, dividido pelo tamanho da amostra no domínio).Em seguida, os pesos amostrais foram calculados em cada um dos domínios para cada grupo de sexo e idade de cada setor censitário amostrado, com base nos dados do Censo IBGE de 2010.

Nos casos em que o coeficiente de variação dos pesos calculado foi maior do que $30 \%$, esses pesos foram aparados por meio de procedimentos, denominados weighttrimming procedures, os quais possibilitam diminuir o impacto de valores extremos, preservar o total da população e reduzir a variabilidade dos pesos.

Após a identificação de estratos, com o efeito de delineamento alterado em razão da presença de valores extremos nos pesos amostrais, foi utilizado, para aparar os pesos, o módulo CalculateSampleWeight do software SISA, fornecido pela empresa QuantitativeSkill, gerando os novos pesos que foram incorporados na base de dados para as análises.

Considerando que em alguns domínios demográficos, por regiões, não se obteve a exata distribuição da amostra originalmente planejada, foi conduzido um processo de pós-estratificação aplicando às observações da amostra os pesos referentes às novas frações de amostragem ajustados por região, sexo e idade seguindo a distribuição da população brasileira encontrada na PNS 2013, o que garantiu uma distribuição da amostra condizente com a distribuição da população brasileira. 


\subsection{Análise de Dados}

O presente estudo realizou uma análise secundária do banco de dados da PNAUM, componente Inquérito populacional. Para atingir os objetivos propostos, foram analisadas variáveis relativas às características socioeconômicas e demográficas; a história e tratamento da diabetes por meio da utilização de insulinas; e o tipos de insulina utilizados pelos entrevistados.

Para dar consecução ao objetivo "a", qual seja a caracterização do perfil socioeconômico e demográfico dos portadores de diabetes mellitus, foram levadas em consideração as variáveis referentes à idade, sexo, nível de escolaridade, raça/cor, classificação ABEP, região e plano de saúde.

Para dar consecução ao objetivo " $b$ ", foi realizado um levantamento quanto à indicação médica de insulinas pelos portadores de diabetes considerando a indicação médica de tratamento, estratificando por meio das variáveis referentes à idade, sexo, nível de escolaridade, raça/cor, Classificação ABEP, região e plano de saúde.

Para dar consecução ao objetivo "c", foi verificado o uso de insulinas pelos portadores de diabetes. Também serão levadas em consideração as variáveis referentes à idade, sexo, nível de escolaridade, raça/cor, classificação ABEP, região e plano de saúde.

Para dar consecução ao objetivo "d”, realizada uma análise descritiva dos tipos de insulina mais utilizados no Brasil.

Os dados foram analisados no programa SPSS, V. 18.3 para Windows (SPSS Inc., Chicago, IL, EUA), utilizando o conjunto de comandos CSPLAN apropriado para a análise de amostras complexas e garantindo a necessária ponderação para dar conta do desenho amostral.

\subsection{Considerações Éticas}

A PNAUM teve aprovação da CONEP pelo número CAAE: 18947013.6.0000.0008, conforme Anexo 02. Ressalta-se que não será feita nenhuma complementação de qualquer natureza, somente a análise do banco de dados. 


\section{RESULTADOS E DISCUSSÃO}

\subsection{ARTIGO}

PREVALÊNCIA DE DIABETES, INDICAÇÃO MÉDICA E UTILIZAÇÃO DE INSULINA NO BRASIL

PREVALENCE OF DIABETES , MEDICAL INDICATION AND INSULIN USE IN BRAZIL

\section{Pedro Felipe Couto Vieira ${ }^{1}$, Noemia Urruth Leão Tavares ${ }^{1}$ \\ 1- Programa de Pós Graduação em Saúde Coletiva, Universidade de Brasília, Unb}

\section{INTRODUÇÃO}

A Diabetes Mellitus (DM) corresponde a uma condição crônico-degenerativa cuja manifestação está associada à ausência e/ou à ação ineficiente de insulina (SBD, 2009) com prevalência mundial estimada em 8,35\% em 2013, o que representa 387 milhões de pessoas. Para a América Central e a América do Sul, essa estimativa é de 24 milhões de pessoas (IDF, 2014). No Brasil, segundo a Pesquisa Nacional de Saúde (PNS) 2013, a prevalência de diabetes é de 6,2\% (IC95\% 5,9-6,6), o que mostra que o diabetes atinge 9 milhões de brasileiros (TAVARES, 2015). Dados do inquérito telefônico do Sistema de Vigilância de Fatores de Risco e Proteção para Doenças Crônicas por Inquérito Telefônico - Vigitel - 2013 confirmaram a tendência crescente na prevalência de diabetes, sendo verificado um aumento de 6,3\% em 2011 para 6,9\% em 2013(BRASIL, 2015).

Essa enfermidade foi responsável por 5,3\% dos óbitos ocorridos em 2011 no país, com taxa de mortalidade de 33,7 óbitos a cada 100 mil habitantes, apesar da redução de 1,7\% ao ano verificado no período 2000-2011 (MALTA, 2014). A taxa mortalidade por complicações agudas do diabetes foi de 2,45 óbitos por 100 mil habitantes em 2010 (IC95\% 2,38-2,52), aumentando exponencialmente com a idade, partindo de quase zero, na faixa etária de menos de cinco anos, e chegando a 39,6 óbitos por 100 mil habitantes (IC95\% 37,3-41,8) na faixa etária dos 80 ou mais anos (KLAFKE, 2014).

O tratamento da DM é complexo e um dos seus objetivos centrais é a obtenção de valores glicêmicos o mais próximos da normalidade. Para tal, é essencial que existam meios eficazes o 
suficiente para que esses valores sejam mantidos em longo prazo (GAEDE et al., 2008), podendo o tratamento estar ou não associado à prescrição de medicamentos ou à reposição insulínica. A insulina exógena é utilizada por todos os diabéticos tipo 1, por diabéticos tipo 2 quando a combinação de medicamentos orais associada a medidas não farmacológicas não for mais efetiva e nos casos de diabetes gestacional (SOCIEDADE BRASILEIRA DE DIABETES, 2011a).

A utilização dos medicamentos é influenciada pelo perfil de morbidade, pela estrutura demográfica, por fatores socioeconômicos, comportamentais e culturais, pelas características do mercado farmacêutico e das políticas governamentais dirigidas ao setor (ARRAIS, 2009; BERTOLDI, 2008). Esse conjunto de fatores precisa ser investigado para permitir a melhor compreensão do papel dos medicamentos no contexto da saúde pública. Dados da PNS 2013 mostram que 80,2\% (IC95\% 78$88,1)$ dos que referiram diagnóstico médico de diabetes estavam em uso de medicamento oral ou insulina para seu tratamento.

Há dois tipos de insulinas: as humanas e as análogas, sendo que o Sistema Único de Saúde (SUS), através da aquisição via Ministério da Saúde (MS), fornecem de forma gratuita apenas as primeiras ficando a cargo das Secretarias de Saúde locais a opção de fornecimento das últimas de acordo com protocolos específicos (SOCIEDADE BRASILEIRA DE DIABETES, 2011b). As primeiras aquisições de insulina NPH pelo Ministério da Saúde ocorreram em 2000, pois até então era fornecida insulina de origem animal. A aquisição e distribuição de insulina Regular teve início apenas em meados de 2008, após a regulamentação da Lei do Diabetes (Lei 11. 347/2006) (BRASIL, 2012e). Esses medicamentos são fornecidos por meio das unidades básicas de saúde, financiados com os recursos da Assistência Farmacêutica Básica e também por meio do Programa Farmácia Popular do Brasil (PFBP).

Os inquéritos populacionais devem constituir parte integrante do sistema nacional de informações em saúde e são essenciais para monitorar condições e situação de saúde com indicadores não disponíveis nas bases de dados secundários dos sistemas de informações10. Portanto, a avaliação de informações oriundas de diferentes modalidades de inquérito torna-se necessária para o aprimoramento do sistema.

A aplicação de questionários para obtenção da informação auto-referida é uma estratégia de menor custo, acessível e rápida para estimar prevalências, apesar de estar sujeita a erros de classificação. No entanto, a acurácia da informação coletada por auto-relato depende das 
características do questionário, da forma de aplicação, da capacitação dos entrevistadores e da população à qual ele é aplicado.

Considerando que os padrões de uso de insulina podem diferir entre regiões e se modificar no decorrer do tempo em função das mudanças do perfil saúde/doença e das políticas de saúde implementadas, são necessárias investigações que permitam identificar, monitorar e produzir informações sobre uso deste medicamento pela população. Nesse sentido, o presente estudo tem por objetivo analisar a prevalência de diabetes, indicação de médica e utilização de insulina pela população adulta brasileira, os fatores determinantes deste uso, segundo as socioeconômicas. Além disso, identificar os tipos de insulina mais utilizados no Brasil.

\section{MÉTODO}

Os dados analisados no presente estudo são oriundos da Pesquisa Nacional sobre Acesso, Utilização e Promoção do Uso Racional de Medicamentos (PNAUM), inquérito domiciliar de base populacional, de delineamento transversal, baseado em amostra probabilística da população brasileira. A coleta de dados foi realizada de setembro de 2013 a fevereiro de 2014. Foram realizadas entrevistas face-a-face nos domicílios com aplicação de questionários cujos dados foram coletados em dispositivo eletrônico. A população em estudo foram os residentes em domicílios particulares permanentes na zona urbana do território brasileiro, sendo incluídos indivíduos de todas as idades.

Para a presente análise foi feito um recorte desse inquérito e analisados os dados da população com idade igual ou superior a 20 anos, que referiram diagnóstico médico de Diabetes.

Para todos os indivíduos que referiam Diabetes foi investigado a indicação médica de uso de insulina a partir da seguinte pergunta: “O(a) Sr.(a) tem indicação médica para usar insulina?” A variável dependente do estudo foi o uso de insulina, obtida pela pergunta: “O(a) Sr.(a) usa insulina?". Também foi solicitado que o entrevistado apresentasse a embalagem do medicamento, a fim de minimizar possíveis erros na anotação dos dados pelo entrevistador. Na ausência da embalagem era anotado o nome comercial ou o princípio ativo segundo o relato do entrevistado. 
As seguintes variáveis independentes foram investigadas: sexo (feminino e masculino); idade (20-49, 50-59, 60-69, 70-79, 80 anos ou mais); cor/autorreferida (branca, não branca). Escolaridade (0 a 8, 9 a 11, 12 anos de estudo ou mais) e classificação econômica segundo a ABEP (http://www.abep.org/) da Associação Brasileira das Empresas de Pesquisa (A/B; C; D/E); plano de saúde (sim/não) e região geográfica de residência (Norte; Nordeste; Sudeste; Sul, Centro-Oeste).

Todas as análises foram realizadas através do pacote estatístico SPSS 18.0 utilizando o conjunto de comandos CSPLAN apropriado para a análise de amostras complexas e garantindo a necessária ponderação para dar conta do desenho amostral.

Foram estimadas as prevalências de uso de insulina segundo as variáveis independentes e os respectivos intervalos de $95 \%$ de confiança (IC95\%).

O presente trabalho foi submetido e aprovado pela Comissão Nacional de Ética em Pesquisa, através do parecer no. 398.131, de 16/9/2013. Todas as entrevistas foram realizadas após leitura do termo de consentimento e assinatura do mesmo por parte do entrevistado ou seu responsável legal no caso de incapazes de responder seu próprio questionário.

\section{RESULTADOS}

Foram entrevistadas 41.403 pessoas, e dos adultos com 20 anos ou mais $(n=32.343) 6,8 \%$ $(\mathrm{IC} 95 \%=6,4-7,2 \%)$ se autodeclararam ter diagnóstico de diabetes, o que representa aproximadamente 9 milhões de brasileiros. Destes, 18,1\% (IC95\%=16,0-20,4\%) tinham indicação médica para utilização de Insulina, estimando-se 1,8 milhão pessoas da população brasileira. Porém, 87,9\% (IC95\%=82,7$91,7 \%$ ) relataram usar insulina e $12,1 \%$ (IC95\%=8,3-17,3\%) não utilizam insulina diariamente.

Tabela 1 - Prevalência auto-referida de diabetes em adultos com 20 anos ou mais segundo características demográficas e socioeconômicas na população brasileira. PNAUM, BRASIL, 2014. 


\section{Variável}

\section{Características demográficas}

Sexo
Masculino
Feminino

\section{Idade}

20 a 49

50 a 59

60 a 69

70 a 79

Acima de 80

Cor da pele

Brancos

Não Brancos
$\% *$

IC95\%

$\leq 0,001$

5,5

7,9

2,3

10,2

18,2

21,5

17,9

7,4

6,7

$4,9 \quad 6,1$

$7,4 \quad 8,4$

$\leq 0,001$

$2,1 \quad 2,7$

$9,1 \quad 11,5$

$16,8 \quad 19,6$

$19,5 \quad 23,5$

$15,2 \quad 21$

0,097

$6,88,1$

$6,2 \quad 7,3$

\section{Características socioeconômicas}

\section{Escolaridade}

0 a 8

9 a 11

12 ou mais

ABEP***

$\mathrm{A} / \mathrm{B}$

$\mathrm{C}$

$\mathrm{D} / \mathrm{E}$

Região

Norte

Nordeste

Sudeste

Sul

Centro-Oeste

Plano de Saúde

Sim

Não

* Percentuais ponderados pelos pesos amostrais.

** Teste do qui-quadrado de Pearson

*** Classificação da Associação Brasileira das Empresas Brasileiras -ABEP 2013 - www.abep.org

De acordo com o apresentado na tabela 01, as mulheres apresentaram prevalência de diagnóstico de DM superior à dos homens $(7,9 \%$ (IC95\%=7,4-8,4\%) e 5,5\% (IC95\%=4,9-6,1\%), respectivamente). 
Ainda, dentre os entrevistados que se autodeclararam ter diagnóstico de Diabetes, a menor prevalência foi a faixa de 20 a 49 anos, compreendendo 2,3\% (IC95\%=2,1-2,7\%). Foi observado na Tabela 01 que não há diferença significativa entre os níveis econômicos da classificação ABEP, nem para a variável escolaridade.

A prevalência de diabetes foi superior na região sudeste $(7,6 \%$; IC95\%=6,8-8,4\%), ao passo que a região que apresentou menor prevalência foi a norte (4,3\%; IC95\%=3,7-5\%).

A Tabela 2 descreve a amostra em relação às variáveis sociodemográficas dos usuários que apresentam indicação médica para uso de insulina para o tratamento de DM. Observou-se que não houve significância nas variáveis sexo, idade, escolaridade e escore ABEP. Destaca-se maior prevalência de indicação médica para uso de insulinas na região sudeste $(20 \%$; IC95\%=16,7-23,8) em relação à região nordeste $(13,4 \%$; IC95\%=10,8-16,5).

Tabela 2 - Prevalência auto-referida de indicação médica para uso de insulina segundo variáveis sóciodemográficas. PNAUM, BRASIL, 2014. 


\begin{tabular}{|c|c|c|c|}
\hline Variável & $\% *$ & IC95\% & p-valor*** \\
\hline \multicolumn{4}{|c|}{ Características demográficas } \\
\hline Sexo & & & 0,901 \\
\hline Masculino & 18,2 & $15,2 \quad 21,6$ & \\
\hline Feminino & 18,0 & $15,5 \quad 20,7$ & \\
\hline Idade & & & 0,586 \\
\hline 20 a 49 & 19,0 & $14,3 \quad 24,9$ & \\
\hline 50 a 59 & 15,6 & $11,8 \quad 20,3$ & \\
\hline 60 a 69 & 19,8 & $16,3 \quad 23,9$ & \\
\hline 70 a 79 & 17,2 & $13,8 \quad 21,3$ & \\
\hline \multicolumn{4}{|l|}{ Acima de 80} \\
\hline Cor da pele & & & 0,464 \\
\hline Brancos & 18,8 & $16,0 \quad 22,0$ & \\
\hline Não Brancos & 17,3 & $14,4 \quad 20,5$ & \\
\hline Escolaridade & & & 0,474 \\
\hline 0 a 8 & 17,5 & $14,9 \quad 20,3$ & \\
\hline 9 a 11 & 19,9 & $16,4 \quad 23,9$ & \\
\hline 12 ou mais & 16,3 & $11,0 \quad 23,6$ & \\
\hline ABEP*** & & & 0,391 \\
\hline $\mathrm{A} / \mathrm{B}$ & 20,8 & $15,8 \quad 26,8$ & \\
\hline $\mathrm{C}$ & 17,5 & $15,2 \quad 20,2$ & \\
\hline $\mathrm{D} / \mathrm{E}$ & 16,4 & $12,3 \quad 21,5$ & \\
\hline Região & & & 0,026 \\
\hline Norte & 13,5 & $8,2 \quad 21,4$ & \\
\hline Nordeste & 13,4 & $10,8 \quad 16,5$ & \\
\hline Sudeste & 20,0 & $16,7 \quad 23,8$ & \\
\hline Sul & 19,3 & $15,6 \quad 23,6$ & \\
\hline Centro-Oeste & 17,3 & $12,9 \quad 22,8$ & \\
\hline Plano de Saúde & & & 0,150 \\
\hline Sim & 20,5 & $16,3 \quad 25,4$ & \\
\hline Não & 17,2 & $15,0 \quad 19,7$ & \\
\hline
\end{tabular}

Percentuais ponderados pelos pesos amostrais.

** Teste do qui-quadrado de Pearson

*** Classificação da Associação Brasileira das Empresas Brasileiras -ABEP 2013 - www.abep.org

Quanto à prevalência dos entrevistados que utilizam insulina, a tabela 03 mostra que não há diferenças estatisticamente significativas entre as variáveis socioeconômicas investigadas. Porém, destaca-se a superioridade de utilização pelo sexo feminino $(89,0 \%$; IC95\%=83-93). A região que 
apresenta maior prevalência de usuários que utilizam insulina é a centro-oeste $(95,1 \%$; IC95\%=84$98,6)$.

Tabela 3 - Prevalência auto-referida de uso de insulina segundo variáveis sóciodemográficas. PNAUM, BRASIL, 2014.

\begin{tabular}{|c|c|c|c|}
\hline \multirow[b]{2}{*}{ Variável } & \multirow[b]{2}{*}{$\% *$} & \\
\hline & & IC95\% & p-valor** \\
\hline \multicolumn{4}{|c|}{ Características demográficas } \\
\hline Sexo & & & 0,410 \\
\hline Masculino & 85,3 & $75,3 \quad 91,7$ & \\
\hline Feminino & 89,0 & $83,0 \quad 93,0$ & \\
\hline Idade & & & 0,690 \\
\hline 20 a 49 & 88,7 & $75,8 \quad 95,2$ & \\
\hline 50 a 59 & 82,7 & $67,6 \quad 91,6$ & \\
\hline 60 a 69 & 88,2 & $75,8 \quad 94,7$ & \\
\hline 70 a 79 & 87,6 & $75,1 \quad 94,3$ & \\
\hline Acima de 80 & 94,7 & $84,7 \quad 98,3$ & \\
\hline Cor da pele & & & 0,698 \\
\hline Brancos & 88,3 & $80,4 \quad 93,2$ & \\
\hline Não Brancos & 86,5 & $78,5 \quad 91,8$ & \\
\hline Escolaridade & & & 0,400 \\
\hline 0 a 8 & 90,2 & $84,0 \quad 94,2$ & \\
\hline 9 a 11 & 83,9 & $72,9 \quad 90,9$ & \\
\hline 12 ou mais & 85,0 & $62,0 \quad 95,2$ & \\
\hline $\mathbf{A B E P} * * *$ & & & 0,147 \\
\hline $\mathrm{A} / \mathrm{B}$ & 89,9 & $77,5 \quad 95,9$ & \\
\hline $\mathrm{C}$ & 83,9 & $76,5 \quad 89,3$ & \\
\hline $\mathrm{D} / \mathrm{E}$ & 94,1 & $85,6 \quad 97,8$ & \\
\hline Região & & & 0,576 \\
\hline Norte & 82,0 & $65,6 \quad 91,6$ & \\
\hline Nordeste & 88,5 & $78,0 \quad 94,3$ & \\
\hline Sudeste & 86,2 & $77,6 \quad 91,9$ & \\
\hline Sul & 89,3 & $78,0 \quad 95,2$ & \\
\hline Centro-Oeste & 95,1 & $84,0 \quad 98,6$ & \\
\hline Plano de Saúde & & & 0,060 \\
\hline Sim & 81,4 & $68,5 \quad 89,8$ & \\
\hline Não & 90,2 & $85,2 \quad 93,7$ & \\
\hline
\end{tabular}


Ao se considerar o denominador insulina $(n=100)$, verifica-se que as insulinas mais consumidas foram as humanas (88\%; IC95\%=80,8-92,7). Já as insulinas análogas correspondem a 12\% (IC95\%=7,3-19,2) do uso. A figura 01evidencia prevalência de uso de insulinas na população de 20 anos ou mais de acordo com o tipo de insulina. É válido salientar que as Insulinas humanas são compostas por NPH e Regular, e estão presentes na Relação Nacional de Medicamentos Essenciais (RENAME). São consideradas análogas as seguintes insulinas: Glargina, Lispro, Glulisina, Aspart e Detemir.

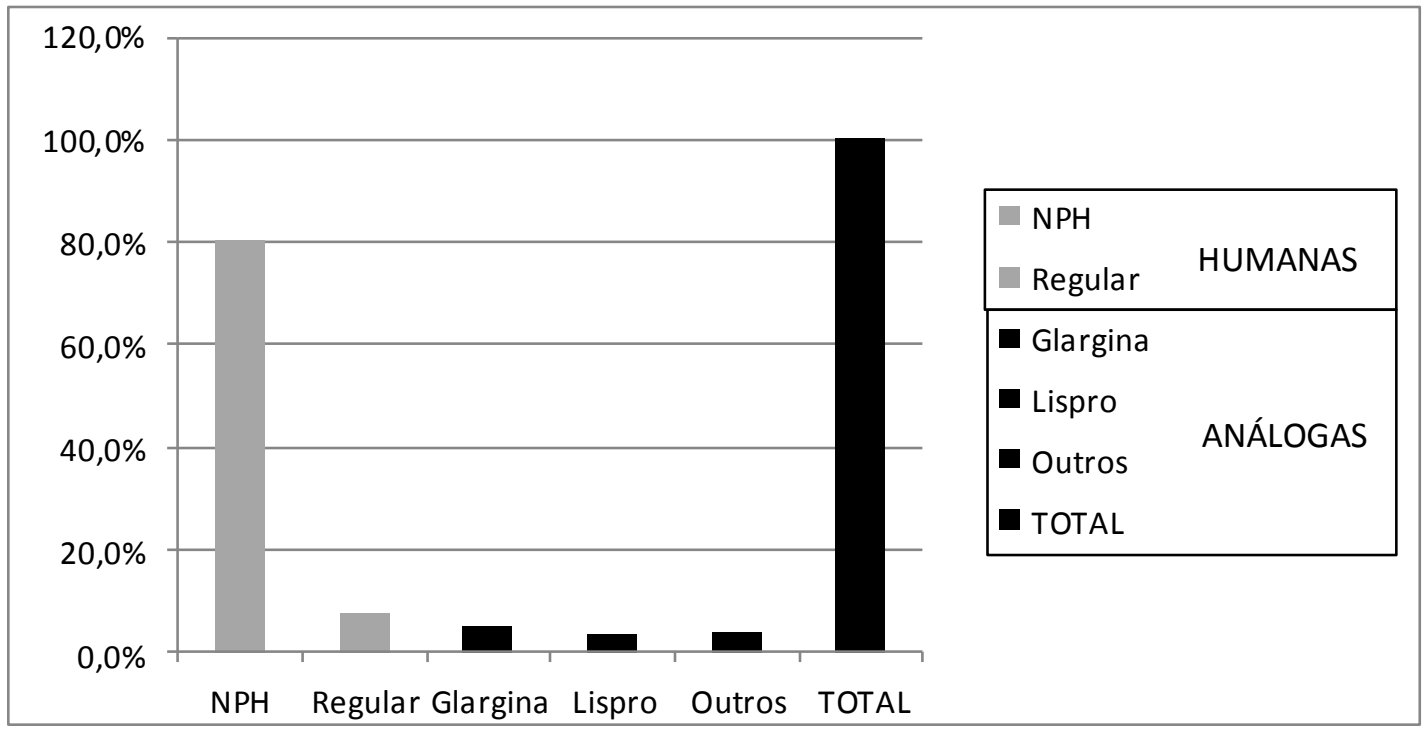

Figura 01: Prevalência auto-referida de uso de insulinas na população de 20 anos ou mais de acordo com o tipo de insulina. PNAUM. BRASIL, 2014.

\section{DISCUSSÃO}


A prevalência de diabetes encontrada $(6,8 \%$; IC95\%=6,4-7,2\%) foi superior à reportada por 6,2\% (IC95\%=5,9-6,6\%) dos entrevistados no Brasil e semelhante a 6,5\% (IC95\%=6,1-7,0\%) da população das capitais na PNS 2013 . Também se mostrou semelhante aos resultados encontrados no Vigitel 2013 (6,9\%; IC95\% 6,5-7,3) e a prevalência indicada pela Pesquisa Nacional por Amostra de Domicílios (PNAD) de 2008 (5,0\% de prevalência bruta e 4,3\% de prevalência padronizada por sexo e idade, para a população $\geq 18$ anos) (MALTA, 2014). Comparando com outros países, a prevalência de diabetes no Brasil encontrada no estudo se mostrou superior à Austrália (4\%) e Itália (5\%), e inferior à Jordânia (7,5\%), Estados Unidos (9,3\%), China (9,7\%), Qatar (13,8\%) e Malásia (22,9\%) (HAZAN, 2015; WAN, 2013; ZINDAH et al., 2008; COWIE et al., 2006; BENER et al., 2009; YANG et al. 2009; RAFANIELLO, 2015).

Foi evidenciado o aumento da prevalência de diabetes com a idade, conforme já foi verificado por Schimt, em 2014, muitas vezes porque com o avanço da idade parece se encontrar no aumento das oportunidades de diagnóstico, tendo em vista que o rastreamento da doença é indicado especialmente para pessoas a partir dos 45 anos, quando aumenta a ocorrência da doença (BRASIL, 2013).

Em relação à faixa etária, observa-se que após os 80 anos ocorre uma tendência à diminuição da prevalência do diabetes, dados estes também encontrados no Projeto SABE e no ISA-SP . Embora não estatisticamente significante, isso pode ser explicado pelo viés de sobrevivência dado a maior mortalidade entre os diabéticos com o avançar da idade (LIMA-COSTA, 2002), pelo grande número de complicações decorrentes da doença (SARTORELLI E FRANCO, 2003).

Não foi observada uma tendência a menor prevalência de diabéticos entre os entrevistados com maior escolaridade, conclusão diferente a dos dados da PNS 2013 em que a escolaridade maior diminuiu a chance de diabetes.

Porém, semelhante à PNS 2013, entre as grandes regiões do país, a maior prevalência de diabetes auto referida foi verificada na região Sudeste (7,6\%; IC95\% 6,8-8,4\%) e a menor, na região Norte $(4,3 \%$; IC95\% 3,7-5\%).

A prevalência de indicação médica de insulina, descrita na tabela 02 , encontrada no estudo foi de $17,5 \%$, o que representa mais de 1 milhão e meio de diabéticos, não havendo diferença significativa nas variáveis sexo, idade, cor da pele, escolaridade e escore ABEP. Um estudo realizado na Itália mostrou que a insulina foi o segundo antidiabético mais prescrito em monoterapia, com um total de 13,3\% de novos utilizadores. Observou-se que não havia diferença significativa entre homens e mulher. Além disso, foi observado que os italianos com idade acima de 74 anos iniciaram tratamento 
predominantemente insulinas humanas ao passo que os italianos com idade inferior à 74 anos já iniciaram tratamento com Insulinas Análogas (RAFANIELLO, 2014).

Quanto à região, o Norte apresentou menor prevalência de prescrição de insulina, em contramão, o sudeste apresentou maior prevalência. Os médicos em geral tendem a se instalar onde há trabalho para sua especialidade, onde se paga melhor, conforme a competição do mercado, onde ele tem possibilidades de aprimoramento e onde há qualidade de vida. Assim, esse lugar costuma coincidir com polos econômicos que concentram hospitais de referência, centros de ensino, programas de Residência Médica e clientela privada (DEMOGRAFIA, 2011). De acordo com dados do Cadastro Nacional de Estabelecimentos de Saúde - CNES, de fevereiro de 2012, enquanto 56,44\% e 4,21\% dos médicos encontram-se nas regiões Sudeste e Norte, respectivamente, a concentração do especialista de endocrinologia e metabologia nessas regiões são ainda mais atenuantes, com $62,75 \%$ no Sudeste e apenas $1,82 \%$ na região norte.

Acerca das desigualdades sociais, os dados da Demografia Médica no Brasil constataram que a demografia médica é ainda mais excludente que aquelas verificadas nas desigualdades regionais. Embora a maioria dos médicos atue no setor público e na rede de assistência médica suplementar, constatou-se que existem diferenças expressivas na disponibilidade e oferta de médicos à população coberta por planos e seguros de saúde e àquela exclusivamente usuária do SUS, concluindo que a primeira tem à sua disposição quatro vezes mais médico do que os cidadãos que dependem exclusivamente do SUS, o que reforça este estudo ao se verificar que a prevalência de indicação médica de insulina foi superior na variável plano de saúde do que na prevalência geral. O nível econômico A/B da ABEP apresentou maior percentual de indicação médica de insulina. A participação do seguro privado no sistema de saúde brasileiro também atua no sentido de acentuar as desigualdades no consumo de serviços de saúde descritas acima. A cobertura de plano de saúde é dependente da renda, sendo expressivamente maior nos grupos com maior poder aquisitivo e entre os residentes do Sudeste (TRAVASSOS, 2000).

As preocupações com os efeitos colaterais da terapêutica com insulina, incluindo hipoglicemia e ganho de peso, pode levar os prestadores de cuidados à saúde por atrasar ou interromper a terapia de insulina para os seus pacientes (DAVIS \& RENDA, 2006; MARRERO, 2007). Além disso, barreiras psicossociais para o início e a continuação podem levar à diminuição de tendências na prevalência de indicação médica e utilização de insulina. 
A insulinização em DM2 apresenta algumas dificuldades tanto por parte dos profissionais de saúde quanto dos pacientes. As principais barreiras citadas pelos profissionais de saúde são, principalmente, a escassez de recursos fornecidos pelos sistemas de saúde, o tempo gasto para esclarecer aos pacientes sobre o uso de insulina, acreditar que o uso de insulina seria o último recurso. Por parte dos pacientes, medo das injeções, percepção do uso de insulina como fracasso no tratamento, associação (falsa) entre o uso de insulina e a piora ou surgimento das complicações crônicas, falta de acesso a profissionais e informações fidedignas, alto custo do tratamento, o aumento de peso e maior frequência de hipoglicemias foram os fatores limitantes para o uso de insulina1. (PEYROT et al, 2006; MEECE, 2006) Nesse contexto, a figura do educador em diabetes, para informar, esclarecer dúvidas e desmistificar alguns aspectos do uso de insulina, entre outras coisas, torna-se essencial (HERMANSEN et al, 2006).

Segundo a tabela 03, 87,6\% relataram usar insulina. De acordo com ROJO-MARTÍNEZ (2013), no período estudado, $2 \%$ da população em geral estava sendo tratado com insulina e 7,1\%, com o Antidiabético oral (ADO). Entre os indivíduos com DM conhecido, 14,9\% estavam utilizando insulina; $68,8 \%$, ADO e $8 \%$, o tratamento combinado com o ADO e insulina.

Observou-se que, embora sem diferenças estatisticamente significativas, maior prevalência de uso de insulina pelas mulheres e entre os pertencentes a grupos etários de maior idade. Resultado semelhante ao estudo realizado nos Estados Unidos (LI, 2012) e na Espanha (ROJO-MARTíNEZ, 2013). A diferença entre as mulheres e os homens tem sido explicada por aspectos socioculturais e biológicos que favoreceriam maior adoecimento, maior autocuidado, maior busca por serviços de saúde e maior exposição a medicamentos entre as mulheres (SANTOS, 2009).

Tanto para homens como para mulheres, a prevalência de uso de insulina se mostrou superior a 80\%, alcançando a meta global da Organização Mundial de Saúde (OMS) na qual prevê 80\% de disponibilidade de tecnologias básicas e de medicamentos genéricos essenciais para o tratamento de doenças crônicas não transmissíveis prioritárias, a preços acessíveis, e, serviços de saúde públicos e privados, incluindo instalações de cuidados primários (MALTA, 2013). A prevalência do uso de medicamentos para as doenças crônicas investigadas pela PNS 2013, incluindo a Diabetes foi elevada - em torno de $80 \%$. O resultado encontrado desse estudo foi levemente superior ao dado encontrado na PNS 2013 que avaliou o uso de medicamentos orais ou insulina para tratamento de diabetes (TAVARES et al, 2015). 
Houve diferenças nas prevalências do uso de medicamentos entre as grandes regiões do país, embora os dados não tenham sido estatisticamente significativos. Tal fato indica desigualdade no processo de cuidado dos pacientes. A região Norte apresentou menores prevalências de diagnóstico e de tratamento medicamentoso. O Centro-Oeste e o Sul, por sua vez, foram as regiões que referiram maior prevalência de uso de insulina. Tal desigualdade regional envolve o acesso a serviços de saúde e diagnóstico médico, uma vez que o Diabetes depende de diagnóstico prévio para indicação e controle no uso de insulina (PNAD, 2013; MENDES, 2014). Em contrapartida

Em geral, essas diferenças nas prevalências de uso de medicamentos em relação à idade, com menor uso entre a população mais jovem pode ser atribuída a uma menor indicação de tratamento medicamentoso e à indicação de terapias não medicamentosas, como alimentação saudável, prática de atividade física, redução do consumo de álcool e não consumo do tabaco (BEAGLEHOLE et al, 2012). Porém, como se pode observar, os dados relacionados à idade não foram significativos, o que pode ter dificultado a relação direta entre consumo de medicamento e idade.

O uso das insulinas humanas (NPH e Regular) apresentou maior percentual de uso (88\%; IC95\%=80,8-92,7). Este dado evidencia que o Brasil apresenta um perfil diferente ao dos países europeus. De acordo com Rafaniello et al., a percentagem de pacientes que iniciam o tratamento com insulinas análogas na Itália aumentou de 84\% em 2010 para 92,4\% em 2012 (P<0,001) e, consequentemente, foi observada a diminuição da utilização de insulinas humanas (de 16\% para 7,6\%, $\mathrm{P}<0,01)$.

Cabe destacar que a Portaria $N^{o}$ 2.583, de 10 de outubro de 2007 define elenco de medicamentos e insumos disponibilizados pelo Sistema Único de Saúde aos usuários portadores de diabetes mellitus, dentre eles, as insulinas Humana NPH e Regular. Estas insulinas fazem parte da Relação Nacional de Medicamentos Essenciais (RENAME) (BRASIL, 2015b). O Ministério da Saúde (MS) vem adquirindo de forma centralizada Insulina NPH desde 2000. A aquisição de distribuição de Insulina Regular pelo governo federal teve início apenas em 2008, após a regulamentação da Lei 11.347/2006. Tal fato por estar diretamente ligado ao elevado percentual de utilização de insulinas humanas pela população brasileira, somando $88 \%$ do total.

Além disso, a partir de 2011 os insulinodependentes passaram obter as insulinas NPH e Regular de forma gratuita nas redes conveniadas ao "Aqui tem Farmácia Popular" por meio do Programa "Saúde não tem preço", o que pode apontar para um maior acesso e utilização desses dois tipos de insulina em relação às análogas. 
Os resultados da pesquisa não diferenciam o Diabetes em tipo 1 e tipo 2, sendo uma limitação do estudo. O DM2 é a forma presente em $90 \%$ a $95 \%$ dos casos e caracteriza-se por defeitos na ação e secreção da insulina (SOCIEDADE BRASILEIRA DE DIABETES, 2014). Existem vários estudos demonstrando que a melhor forma de iniciar a insulinização em DM2 é com insulina basal (glargina, detemir ou NPH), aplicada uma vez ao dia, na hora de dormir (bed time), mantendo os antidiabéticos orais durante o dia (YKI-JARVINEN et al, 2007). O uso precoce e intensivo de insulina como primeira opção terapêutica tem sido associado a controle glicêmico mais precoce e duradouro, quando comparado aos hipoglicemiantes orais, o que sugere um papel da insulina na preservação da função das células betapancreáticas (AMERICAN GERIATRICS SOCIETY, 2003). Estes dados somados ao fato de a insulina NPH compor a RENAME pode explicar o elevado percentual de utilização deste tipo de insulina no presente estudo.

\section{CONCLUSÃO}

Os resultados encontrados demonstram a alta prevalência de utilização de insulinas pela população brasileira para tratar a Diabetes, indicando um melhor acesso ao tratamento medicamentoso para o tratamento de diabetes.

Acompanhar as tendências de uso de insulinas entre as pessoas com diagnóstico médico de diabetes pode fornecer informações úteis para os médicos em sua rotina de gerenciamento de pacientes e para o norteamento de políticas públicas voltadas para intervenção de agravos relacionados ao diabetes.

É necessária a elaboração de programas de educação em saúde com o intuito de mostrar os avanços farmacêuticos aos médicos e pacientes no que tange à prescrição e administração de insulinas, objetivando superar as barreiras psicossociais para que haja o correto uso de insulina e consequente controle glicêmico. 


\section{REFERÊNCIAS}

1. Arrais PSP. Medicamentos: consumo e reações adversas - um estudo de base populacional. Fortaleza: Edições UFC; 2009.

2. Barros MBA. Inquéritos domiciliares de saúde: potencialidades e desafios. Rev Bras Epidemiol. 2008;11 Suppl 1:6-19.

3. Beaglehole R, Bonita R, Horton R, Ezzati M, Bhala N, Amuyunzu-Nyamongo M, et al. Measuring progress on NCDs: one goal and five targets. Lancet. 2012 Oct;380(9850):1283-5.

4. Bener A, Zirie M, Janahi IM, Al-Hamaq AO, Musallam M, Wareham NJ. Prevalence of diagnosed and undiagnosed diabetes mellitus and its risk factors in a population-based study of Qatar. Diabetes Res Clin Pract. 2009 Apr; 84(1): 99-106.

5. Bertoldi AD, Barros AJD, Hallal PC, Lima RC. Utilização de medicamentos em adultos: prevalência e determinantes individuais. Rev Saúde Pública 2004; 38:228-38.

6. BRASIL. Portaria $\mathrm{n}^{\circ}$ GM/MS 2.583, de 10 de Outubro de 2007. Define o elenco de medicamentos e insumos disponibilizados pelo SUS aos usuários portadores de diabetes mellitus. Brasília, DF, 2007. Disponível em: <http://189.28.128.100/dab/docs/legislacao/ portaria2583_10_10_2007.pdf >. Acesso: 10 MAR. 2016.

7. BRASIL. Ministério da Saúde. Secretaria de Ciência, Tecnologia e Insumos Estratégicos. Departamento de Assistência Farmacêutica. Relatório Anual de Gestão 2011. Brasília, 2012.

8. BRASIL. Ministério da Saúde. Secretaria de Atenção à Saúde. Departamento de Atenção Básica. Estratégias para o cuidado da pessoa com doença crônica: diabetes mellitus [Internet]. Brasília: Ministério da Saúde; 2013 [citado 2016 abr 05]. 160 p. (Cadernos de Atenção Básica; 36). Disponível em: http://bvsms. saude.gov.br/bvs/publicacoes/estrategias_cuidado_pessoa_diabetes_mellitus_cab36.pdf 
9. BRASIL. Ministério da Saúde. Secretaria de Vigilância em Saúde. Secretaria de Ciência, Tecnologia e Insumos Estratégicos. Vigitel Brasil: vigilância de fatores de risco e proteção para doenças crônicas por inquérito telefônico: estimativas sobre frequência e distribuição sociodemográfica do uso e fontes de obtenção dos medicamentos para tratamento da hipertensão e diabetes nas capitais dos 26 estados brasileiros e do Distrito Federal, 2011 a 2013. Brasília, DF: Ed. do Ministério da Saúde, 2015a.

10. Brasil. Ministério da Saúde. Secretaria de Ciência, Tecnologia e Insumos Estratégicos. Departamento de Assistência Farmacêutica e Insumos Estratégicos. Relação Nacional de Medicamentos Essenciais : RENAME 2014 / Ministério da Saúde, Secretaria de Ciência, Tecnologia e Insumos Estratégicos, Departamento de Assistência Farmacêutica e Insumos Estratégicos. - 9. ed. - Brasília : Ministério da Saúde, 2015b. 228 p.

11. Chrestani MA, Santos IS, Matijasevich AM. Hipertensão arterial sistêmica auto-referida: validação diagnóstica em estudo de base populacional. Cad Saúde Pública. 2009;25(11):23952406

12. Cowie CC, Rust KF, Byrd-Hold DD, Eberhardt MS, Flegal KM, Engelgau MM, et al. Prevalence of diabetes and impaired fasting glucose in adults in the U.S. population: Nacional Health And Nutrition Examination Survey 1999-2002. Diabetes Care. 2006 Jun;29(6): 1263-8.

13. Davis, S. N., \& Renda, S. M. (2006). Psychological insulin resistance: overcoming barriers to starting insulin therapy. The Diabetes Educator, 32(Suppl 4), 146S-152S.

14. DEMOGRAFIA MÉDICA NO BRASIL: dados gerais e descrições de desigualdades. Coordenação: Mário Scheffer; Aureliano Biancarelli e Alex Cassenote. São Paulo: Conselho Regional de Medicina do Estado de São Paulo e Conselho Federal de Medicina, 2011. v. 1, 117p. 
15. GAEDE, P.; LUN-ANDERSWN, H; PARVING, H; PEDERSEN, O. Effect of a Multifactorial Intervention on Mortality in Type 2 Diabetes. The New England Journal of Medicine, Nova Inglaterra, v. 358, n. 6, p. 580-591, 2008.

16. Hasan, Syed S., Clavarino, Alexandra M., Mamun, Abdullah A. and Kairuz, Therese (2015) A comparative drug utilisation study of the treatment of diabetes in Malaysia and Australia. Australasian Medical Journal, 8 6: 179-188. doi:10.4066/AMJ.2015.2330.

17. Hermansen K, Davies M, Derezinski T, Martinez Ravn G, Clauson P, Home P. A 26-week, randomized, parallel, treat-to-target trial comparing insulin detemir with NPH insulin as add-on therapy to oral glucose-lowering drugs in insulin-naive people with type 2 diabetes. Diabetes Care 2006;29:1269-74.

18. Instituto Brasileiro de Geografia e Estatística. Pesquisa Nacional de Saúde 2013: percepção do estado de saúde, estilos de vida e doenças crônicas - Brasil, Grandes Regiões e Unidades da Federação [Internet]. Rio de Janeiro: Instituto Brasileiro de Geografia e Estatística; 2014 [citado 2016 mar 20]. 181 p. Disponível em: ftp://ftp.ibge.gov.br/PNS/2013/ pns2013.pdf

19. Instituto Brasileiro de Geografia e Estatística. Pesquisa Nacional por Amostra de Domicílios: um panorama da saúde no Brasil - acesso e utilização dos serviços, condições de saúde e fatores de risco e proteção à saúde 2008. Rio de Janeiro: Instituto Brasileiro de Geografia e Estatística; 2010.

20. International Diabetes Federation. IDF Diabetes Atlas [Internet]. 6th ed. Brussels: International Diabetes Federation; 2014 [cited 2014 Jan 19]. Available from :http://www.idf.org/diabetesatlas

21. Klafke A, Duncan BB, Rosa RS, Moura L, Malta DC, Schmidt MI. Mortalidade por complicações agudas do diabetes melito no Brasil, 2006-2010. Epidemiol Serv Saude. 2014 julset;23(3):455-62. 
22. Lebrão ML, Laurenti R. Condições de saúde. In: Lebrão ML, Duarte YA, organizadores. O Projeto SABE no Município de São Paulo: uma abordagem inicial. Brasília: Organização Pan Americana da Saúde/Organização Mundial da Saúde; 2003. p.75-91.

23. Lima-Costa MF, Barreto S, Giatti L. A situação socioeconômica afeta igualmente a saúde de idosos e adultos mais jovens no Brasil? Um estudo utilizando dados da Pesquisa Nacional por Amostra de Domicílios (PNAD 98). Ciênc Saúde Coletiva 2002; 7:813-24.

24. Malta DC, Moura L, Prado RR, Escalante JC, Schmidt MI, Duncan BB. Mortalidade por doenças crônicas não transmissíveis no Brasil e suas regiões, 2000 a 2011. Epidemiol Serv Saude. 2014 dez;23(4):599-608.

25. Malta DC; Silva Jr JB. O Plano de Ações Estratégicas para o Enfrentamento das Doenças Crônicas Não Transmissíveis no Brasil e a definição das metas globais para o enfrentamento dessas doenças até 2025: uma revisão. Epidemiol. Serv. Saúde v.22 n.1 Brasília mar. 2013

26. Marrero, D. G. (2007). Overcoming patient barriers to initiating insulin therapy in type 2 diabetes mellitus. Clinical Cornerstone, 8, 33-40.

27. Meece J. Dispelling myths and removing barriers about insulin in type 2 diabetes. Diabetes Educ 2006;32(1 Suppl):9S-18S.

28. Mendes LVP, Emmerick ICM, Luiza VL. Uso de medicamentos entre portadores de doenças crônicas: um estudo observacional no estado do Espírito Santo. Rev Bras Farm. 2014 abrjun;95(2):732-47.

29. Peyrot M, Rubin RR, Lauritzen T, Skovlund SE, Snoek FJ, Matthews DR, et al. Patient and provider perceptions of care for diabetes: results of the cross-national DAWN Study. Diabetologia 2006;49:279-88. 
30. Rafaniello C, Arcoraci V, Ferrajolo C, Sportiello L, Sullo MG, Giorgianni F, et al. Trends in the prescription of antidiabetic medications from 2009 to 2012 in a general practice of Southern Italy: a population-based study. Diabetes Res Clin Pract. 2015 Apr;108(1):157-63

31. Rojo-Martínez G, Valdés S, Colomo N, Lucena MI, Gaztambidead S, et al. Consumo de fármacos relacionados con el tratamiento de la diabetes mellitus y otros factores de riesgo cardiovascular en la población española. Estudio Di@bet.es. Rev Esp Cardiol. 2013;66:854-63 Vol. 66 Núm.11 DOI: 10.1016/j.recesp.2013.05.027

32. Santos DB, Barreto ML, Coelho HL. Utilização de medicamentos e fatores associados entre crianças residentes em áreas pobres. Rev Saúde Pública 2009; 43:768-78.

33. SCHMIDT, M. I. et al. Doenças crônicas não transmissíveis no Brasil: carga e desafios atuais. The Lancet, p. 61-74, 2011.

34. SOCIEDADE BRASILEIRA DE DIABETES. Diretrizes da Sociedade Brasileira de Diabetes 2009. 3. ed. São Paulo: A. Araújo Silva Farmacêutica, 2009.

35. SOCIEDADE BRASILEIRA DE DIABETES. Algoritmo para o tratamento do diabetes tipo 2. Atualização 2011. São Paulo, 2011a.'

36. SOCIEDADE BRASILEIRA DE DIABETES. Revisão sobre análogos de insulina: indicações e recomendações para a disponibilização pelos serviços públicos de saúde. Sociedade Brasileira de Diabetes, $2011 \mathrm{~b}$

37. Sociedade Brasileira de Diabetes. Diretrizes da Sociedade Brasileira de Diabetes: 2013-2014. Organização José Egidio Paulo de Oliveira, Sérgio Vencio. - São Paulo: AC Farmacêutica, 2014.

38. Schmidt MI, Hoffmann JF, Diniz MFS, Lotufo PA, Griep RH, Bensenor IM, et al. High prevalence of diabetes and intermediate hyperglycemia - The Brazilian Longitudinal Study of Adult Health (ELSA-Brasil). Diabetol Metab Syndr. 2014 Nov;6(123):1-9. 
39. Sartorelli DS, Franco LJ. Tendências do diabetes mellitus no Brasil: o papel da transição nutricional. Cad Saúde Pública 2003; 19 Suppl 1:29-36.

40. Tavares NUL, Costa KS, Mengue SS, Vieira, MLFP, Malta, DC, Silva Júnior, JB. Uso de medicamentos para tratamento de doenças crônicas não transmissíveis no Brasil: resultados da Pesquisa Nacional de Saúde, 2013. Epidemiologia e Serviços de Saúde, v. 24, p. 315-323, 2015.

41. Travassos C, Oliveira EXG, Viacava F. Desigualdades geográficas e sociais no acesso aos serviços de saúde no Brasil: 1998 e 2003. Cienc Saude Colet. 2006 out-dez;11(4):975-86.

42. Wan Nazaimoon WM, Md Isa SH, Wan Mohamad WB, et al. Prevalence of diabetes in Malaysia and usefulness of HbA1c as a diagnostic criterion. Diabet Med. 2013;30(7):825-8.

43. Yang W, Li J, Weng J, Jia W, Ji L, Xiao J, et al. Prevalence of diabetes among men and women in China. N Engl J Med. 2010 Mar 25;362 (12): 1090-101

44. Zindah M, Belbeisi A, Walke H, Mokdad AH. Obesity and diabetes in Jordan: Findings from the behavioral risk factor surveillance system, 2004. Prev Chronic Dis. 2008 Jan; 5(1):A17.

45. Yki-Järvinen H, Juurinen L, Alvarsson M, Bystedt T, Caldwell I, Davies M,et al. Initiate Insulin by Aggressive Titration and Education (INITIATE): a randomized study to compare initiation of insulin combination therapy in type 2 diabetic patients individually and in groups. Diabetes Care 2007;30:1364-9. 


\section{CONSIDERAÇÕES FINAIS}

Apesar de algumas diferenças quanto ao uso de insulinas entre as grandes regiões do país indicarem desigualdades no processo de cuidado aos pacientes portadores de Diabetes, a política adotada pelo Ministério da Saúde se mostrou robusta, uma vez que os resultados deste estudo demonstram alta prevalência de utilização de insulinas pela população brasileira para tratar esse agravo, indicando um melhor acesso ao tratamento medicamentoso.

Muito se tem investido para assegurar o acesso a medicamentos essenciais, dentre eles a insulina, uma vez que o acesso a esses medicamentos consta nas metas para o desenvolvimento do milênio. A implantação do Programa Saúde Não tem Preço é um dos esforços do MS para assegurar este acesso, beneficiando um maior contingente populacional.

Este estudo mostra que as insulinas mais utilizadas contam na RENAME, somando um percentual de $88 \%$ do total. Isso pode estar relacionado, em grande parte, à regularidade no abastecimento de insulina humana na rede pública pelo Ministério da Saúde por meio da atenção básica e do Programa Farmácia Popular.

A indicação médica de insulinas mostrou-se desigual entre as regiões do país, o que reflete principalmente em desigualdade relacionada à distribuição da oferta de serviços e dos profissionais médicos. Para que haja uma ampliação gradativa e homogênea do acesso à insulina no Brasil é necessário esforços para que a população das regiões mais desfavorecidas tenha um maior acesso aos serviços de saúde, em especial, ao atendimento médico, a fim de que nos próximos anos se possa ter alto nível de cobertura para o tratamento de diabetes. Considerando que o início do processo de insulinização dos pacientes assim como sua manutenção se dá pelos médicos endocrinologistas, constata-se que há necessidade de implementação de Políticas Públicas que melhore a distribuição e fixação desses profissionais no País, visando facilitar seu acesso.

Uma das metas globais da OMS é a previsão de $80 \%$ de disponibilidade de tecnologias básicas e de medicamentos genéricos essenciais para o tratamento de doenças crônicas não transmissíveis prioritárias, a preços acessíveis, e, serviços de saúde públicos e privados, incluindo instalações de cuidados primários. No que tange à insulina, os resultados apontam alcance da meta no país uma vez que o estudo mostra que a prevalência de uso de insulina foi de $87,6 \%$. 
Constata-se que há necessidade de melhorar a qualificação dos profissionais da Atenção Básica no que tange à utilização de insulina, e visando a integralidade da atenção aos portadores de doenças crônicas não-transmissíveis.

Acompanhar as tendências de uso de insulinas entre as pessoas com diagnóstico médico de diabetes pode fornecer informações úteis para os médicos em sua rotina de gerenciamento de pacientes e para o norteamento de políticas públicas voltadas para intervenção de agravos relacionados ao diabetes.

É necessária a elaboração de programas de educação em saúde com o intuito de mostrar os avanços farmacêuticos aos médicos e pacientes no que tange à prescrição e administração de insulinas, objetivando superar as barreiras psicossociais para que haja o correto uso de insulina e consequente controle glicêmico. 


\section{REFERÊNCIAS BIBLIOGRÁFICAS}

1. Cesse EAP, Freese E. Características e determinantes do padrão brasileiro deocorrência das DCNT no século XX. In: FREESE, E. Epidemiologia, políticas edeterminantes das doenças crônicas não transmissíveis no Brasil. Recife: Ed. Universitária da UFPE, 2006. cap. 2, p. 4772.

2. Brasil. Secretaria de Vigilância à Saúde. Plano de Ações estratégicas para o enfrentamento das Doenças Crônicas Não Transmissíveis no Brasil, 2011-2022. Brasília, DF, 2011

3. Shaw JE, Sicree RA, Zimmet PZ. Global estimates of the prevalence of diabetes for 2010 and 2030. Diabetes Research and Clinical Practice, Oxford, v. 87, p. 4-14, 2010.

4. Tavares NUL, Costa KS, Mengue SS, Vieira, MLFP, Malta, DC, Silva Júnior, JB. Uso de medicamentos para tratamento de doenças crônicas não transmissíveis no Brasil: resultados da Pesquisa Nacional de Saúde, 2013. Epidemiologia e Serviços de Saúde, v. 24, p. 315-323, 2015.

5. Gaede P, Lun-Anderswn H, Parving H, Pedersen O. Effect of a Multifactorial Intervention on Mortality in Type 2 Diabetes. The New England Journal of Medicine, Nova Inglaterra, v. 358, n. 6, p. 580-591, 2008.

6. Sociedade Brasileira de Diabetes. Algoritmo para o tratamento do diabetes tipo 2. Atualização 2011. São Paulo, 2011.

7. Sociedade Brasileira de Diabetes. Revisão sobre análogos de insulina: indicações e recomendações para a disponibilização pelos serviços públicos de saúde. Sociedade Brasileira de Diabetes, 2011.

8. Hogerzeil HV, Mirza Z. The world medicines situation 2011: access to 
essential medicines as part of the right to health. Geneva: World Health Organization, 2011. $14 \mathrm{p}$.

9. Brasil. Constituição da República Federativa do Brasil. Brasília: Senado Federal, 1988.

10. Brasil. Lei $\mathrm{n}^{\mathrm{o}}$ 8.069, de 13 de julho de 1990. Dispõe sobre o Estatuto da Criança e do Adolescente e dá outras providências. Brasília, 1990.

11. Brasil. Ministério da Saúde. Portaria GM n 371, de 04 de março de 2002. Institui o Programa Nacional de Assistência Farmacêutica para Hipertensão Arterial e Diabetes Mellitus, como parte integrante do Plano Nacional de Reorganização da Atenção a Hipertensão Arterial e Diabetes Mellitus. Diário Oficial da União, 2002.

12. Brasil. Lei Federal n ${ }^{\circ}$ 11. 347, de 27 de setembro de 2006. Dispõe sobre a distribuição gratuita de medicamentos e materiais necessários à sua aplicação e à monitoração da glicemia capilar aos portadores de diabetes inscritos em programas de educação para diabéticos. Diário Oficial da União, 2006

13. Brasil. Ministério da Saúde. Portaria n 2. 583, de 10 de outubro de 2007. Define elenco de medicamentos e insumos disponibilizados pelo Sistema Único de Saúde, nos termos da Lei no 11. 347, de 2006, aos usuários portadores de diabetes mellitus. Diário Oficial da União, 2007.

14. Brasil. Ministério da Saúde. Portaria $n^{\circ} 1.555$, de 30 de junho de 2013. Aprova as normas de financiamento e execução do Componente Básico da Assistência Farmacêutica. Diário Oficial da União. Brasília - DF, 2013.

15. BRASIL. Conselho Nacional de Saúde. Resolução n. 338, de 06 de maio de 2004. Aprova a Política Nacional de Assistência Farmacêutica. Diário Oficial da União, Poder Executivo, Seção 1 n. 96, 20 de maio de 2004. Brasília: Ministério da Saúde, 2004. 
16. Arrais PSP. Medicamentos: consumo e reações adversas - um estudo de base populacional. Fortaleza: Edições UFC; 2009.

17. Brasil. Ministério da Saúde. Portaria No 2.077, DE 17 DE SETEMBRO DE 2012. Institui a Pesquisa Nacional sobre Acesso, Utilização e Promoção do Uso Racional de Medicamentos no Brasil (PNAUM). Diário Oficial da União. Brasília - DF, 2012.

18. Sociedade Brasileira de Diabetes. Diretrizes da Sociedade Brasileira de Diabetes 2009. 3. ed. São Paulo: A. Araújo Silva Farmacêutica, 2009.

19. Brasil. Ministério da Saúde. Secretaria de Atenção à Saúde. Departamento de Atenção Básica. Diabetes Mellitus. 56 p. il. - (Cadernos de Atenção Básica, n. 16) (Série A. Normas e Manuais Técnicos). Brasília, 2006.

20. Federação Internacional de Diabetes. The Diabetes Atlas. 5. ed. Brussels, 2011. Disponível em: <http://www.idf.org/media-events/pressreleases/ 2011/diabetes-atlas-5th-edition>. Acesso em: 12 nov. 2013.

21. Brasil. Ministério da Saúde. Secretaria de Vigilância em Saúde. Secretaria de Ciência, Tecnologia e Insumos Estratégicos. Vigitel Brasil: vigilância de fatores de risco e proteção para doenças crônicas por inquérito telefônico: estimativas sobre frequência e distribuição sociodemográfica do uso e fontes de obtenção dos medicamentos para tratamento da hipertensão e diabetes nas capitais dos 26 estados brasileiros e do Distrito Federal, 2011 a 2013. Brasília, DF: Ed. do Ministério da Saúde, 2015.

22. Associação Americana de Diabetes. Standards of Medical Care In Diabetes - 2011. Diabetes Care, Alexandria, v. 34, n. 1, 51 p., 2011. 
23. Associação Americana de Diabetes. Statement: Standards of Medical Care in Diabetes. Diabetes Care, Alexandria, v. 33, n. 1, 51 p., 2010.

24. Sociedade Brasileira de Diabetes. Diretrizes da Sociedade Brasileira de Diabetes 2009. 3. ed. São Paulo: A. Araújo Silva Farmacêutica, 2009.

25. International Diabetes Federation (IDF). The Global Burden 2011. Disponível em: http://www. idf. org/diabetesatlas/5e/the-global-burden. Acesso em 18 jan. 2016.

26. Schmidt MI. et al. Doenças crônicas não transmissíveis no Brasil: carga e desafios atuais. The Lancet, p. 61-74, 2011.

27. Rosa RS, Schmidt MI. Diabetes Mellitus: magnitude das hospitalizações na rede pública do Brasil, 1999-2001. Epidemiologia e Serviços de Saúde. v. 17, n. 2. p. 131-4, 2008

28. Shah BR. et al. Diabetic patients with prior specialist care have better glycaemic control than those with prior primary care. Journal of Evaluation in Clinical Practice, Oxford, v.11, n. 6, p. $568-575,2005$.

29. Menzin J. et al. Relationship between glycemic control and diabetes-related hospital costs in patients with type 1 or type 2 diabetes mellitus. Journal of Managed Care Pharmacy, Alexandria, v. 16, n. 4, p. 264-275, 2010.

30. Dullius J. Diabetes Mellitus: saúde, educação, atividades físicas. Brasília: Ed. UnB, 2007.

31. Associação Americana de Diabetes. Standards of Medical Care In Diabetes - 2013. Diabetes Care, Estados Unidos, v. 36, n. 1, 51 p., 2013.

32. Marcones, JAM. Diabetes Melito: Fisiopatologia e Tratamento. Revista da Faculdade de Ciências Médicas de Sorocaba, São Paulo, v.5, p.18-26, 2003. 
33. Instituto Brasileiro de Geografia e Estatística. Pesquisa Nacional de Saúde 2013: percepção do estado de saúde, estilos de vida e doenças crônicas - Brasil, Grandes Regiões e Unidades da Federação. Rio de Janeiro: IBGE; 2014.

34. Oliveira MA; Bermudez JAZ, Castro CGSO. Assistência Farmacêutica e acesso a medicamentos. Rio de Janeiro: Editora Fiocruz, 2007.

35. Barros JAC. Políticas Farmacêuticas: A Serviço de Interesses da Saúde?. Brasília,DF: UNESCO, 2004

36. Sociedade Brasileira De Vigilância De Medicamentos. O que é uso racional de medicamentos. Acción Internacional para La Salud- América Latina y El Caribe, São Paulo: Sobravime, 2001.

37. Instituto Brasileiro de Geografia e Estatística. Síntese de Indicadores Sociais: Uma análise das condições de vida da população brasileira. Rio de Janeiro; 2013.

38. Leach B, Paluzzi JE, Munderi P. Prescription for healthy development: increasing access to medicines. UN Millennium Project, London, 2005. Disponível em: $<$ http://www.unmillenniumproject.org/documents/TF5-medicines-Complete.pdf $>$. Acesso em: 03 mar. 2016.

39. Conselho Nacional Dos Secretários De Saúde. O Desafio do Acesso aos Medicamentos: Relatório do Seminário Internacional de Assistência Farmacêutica. $1^{\text {a }}$ ed., Brasília, DF, 2010. (CONASS documenta, n.20).

40. Wirtz VJ, et al. Medicines in Mexico, 1990-2004: systematic review of research on access and use. Salud pública de México, Cuernavaca, vol.50,supl. 4, 2008. 
41. Brasil. Secretaria de Políticas de Saúde. Política Nacional de Medicamentos. Brasília, DF: Ministério da Saúde, 1999.

42. Pepe EVD, Castro CGSO, Luiza LV. A Relação Nacional de Medicamentos Essenciais, um instrumento da política nacional de medicamentos na garantia do acesso In: Buss PM, Carvalheiro JR, Romero CNP. Medicamentos no Brasil: Inovação e Acesso. Rio de Janeiro: Editora Fiocruz, 2008.

43. Brasil. Decreto $n^{\circ} 7508$, de 28 de junho de 2011. Regulamenta a Lei $n^{\circ} 8$. 080, de 19 de setembro de 1990, para dispor sobre a organização do Sistema Único de Saúde - SUS, o planejamento da saúde, a assistência à saúde e a articulação interfederativa, e dá outras providências. Diário Oficial da União, 2011.

44. Santos-Pinto CDB. et al. Quem acessa o programa farmácia Popular no Brasil ? Aspectos do fornecimento público de medicamentos. Ciência \& Saúde Coletiva, Rio de Janeiro, v. 16, supl. 6, p. 2963-2973, 2011.

45. Galindo AJA. Avaliação do controle clínico de hipertensos e diabéticos cadastrados no Programa de Acompanhamento da Atenção Básica (HIPERDIA) no município de Arcoverde Pernambuco. 2010. Dissertação (Mestrado Profissional em Saúde Pública) Departamento de Saúde Coletiva, Centro de Pesquisa Aggeu Magalhães, Fundação Oswaldo Cruz. Recife, 2010.

46. Chaves CG. et al. Indicadores de uso racional de medicamentos e acesso a medicamentos: um estudo de caso. Revista Brasileira de Farmácia, Rio de Janeiro, v.86, n.3,p.97-103, 2005.

47. Brasil. Ministério da Saúde. HÓRUS - Sistema Nacional de Gestão da Assistência Farmacêutica. Brasília, 2009. Disponível em: <http://portal.saude.gov.br/portal/saude/ profissional/visualizar_texto.cfm>. Acesso em: 4 abr. 2016.

48. Brasil. Ministério da Saúde. Formulário Terapêutico Nacional 2010. Brasília, DF: Ed. do Ministério da Saúde, 2010. 
49. Lyra R, Cavalcanti N, Mazza F. Diabetes: perguntas e respostas. Itapevi, São Paulo: A. Araújo Silva Farmacêutica, 2009.

50. Boletim Brasileiro de Avaliação de Tecnologias em Saúde. Brasília: Agência Nacional de Vigilância Sanitária, n. 13, ano V, dez. 2010. 32 p. Disponível em: http://bvsms. saude. gov. br/bvs/ct/pdf/brats2010_n13. pdf. Acesso em 26 jan. 2016

51. Louly G. Parecer Técnico Científico sobre o uso de insulinas recombinantes análogas à humana de curta duração (Asparte e Lispro) no tratamento do Diabetes mellitus Tipo 1. Brasília, 2009.

52. Brasil. Advocacia Geral da União. Parecer No 1481/2012-AGU/CONJURMS/ RAB: A atenção para o tratamento de Diabetes Mellitus no âmbito do SUS e as denominas insulinas análogas uma análise a respeito da eficácia, segurança e custoefetividade. 2012

53. Brasil. Ministério da Saúde. Portaria No 31, de 4 de Setembro de 2014. Torna pública a decisão de não incorporar as insulinas análogas para diabetes mellitus tipo I no âmbito do Sistema Único de Saúde - SUS.. Brasília - DF, 2014.

54. Federação Internacional de Diabetes. The economic impacts of diabetes. Brussels, 2009. Disponível em: 〈http://www.idf.org/diabetesatlas/economicimpacts-diabetes>. Acesso em: 12 nov. 2015.

55. Agência de Vigilância Sanitária. Preços máximos de medicamentos - em monodrogas - por princípio ativo, para compras públicas/ Preço Fábrica (PF) e Preço Máximo de Venda ao Governo (PMVG), 2013. Disponível em:

<http>//s.anvisa.gov.br/wps/s/r/f6>. Acesso em: 23 nov. 2015

56. Brasil. Ministério da Saúde. Nota técnica no 26/ 2011/ CNHD/ DAB/ SAS/ MS. 2011 
57. Brasil. Governo Federal. Lei 9.787, de 10 de fev. 1999. Estabelece o Medicamento Genérico. Brasília, DF: Ministério da Saúde, 1999b. Disponível em:< http://portal.saude. gov.br / portal/arquivos/pdf/lei_9787.PDF>. Acesso em: 10 mar. 2016.

58. Organização Pan-Americana da Saúde. Inquérito sistemático de serviços e pesquisa domiciliar de acesso a medicamentos. In: .Avaliação da Assistência Farmacêutica no Brasil: Estrutura, Processo e Resultados. Brasília : Organização Pan-Americana da Saúde; Ministério da Saúde, 2005

59. Souza MLP, Garnelo L. —É muito dificultoso!": etnografia dos cuidados a pacientes com hipertensão e/ou diabetes na atenção básica, em Manaus, Amazonas, Brasil. Cad. Saúde Pública, Rio de Janeiro, v.24, supl.1, 2008.

60. Brasil. Ministério da Saúde. Diretrizes para a estruturação das Farmácias no âmbito do Sistema Único de Saúde. Brasília, DF, 2009.

61. Brasil. Ministério da Saúde. Portaria GM nº 204, de 29 de janeiro de 2007. Regulamenta o financiamento e a transferência dos recursos federais para as ações e os serviços de saúde, na forma de blocos de financiamento, com o respectivo monitoramento e controle. Diário Oficial da União, 2007

62. Brasil. Ministério da Saúde. Portaria no 1554 de 30 de julho de 2013. Dispõe sobre as regras de financiamento e execução do Componente Especializado da Assistência Farmacêutica no âmbito do Sistema Único de Saúde (SUS). Diário Oficial da União, Poder Executivo, Brasília 2013.

63. Brasil. Decreto ${ }^{\circ}$. 5. 090, de 20 de maio de 2004. Regulamenta a Lei 10. 858, de 20 de maio de 2004, e institui o programa "Farmácia Popular do Brasil”, e dá outras providências. Diário Oficial da União, Poder Executivo, Brasília, 2004. 
64. Brasil. Ministério da Saúde. Portaria nº . 491, de 09 de março de 2006. Dispõe sobre a expansão do Programa "Farmácia Popular do Brasil". Diário Oficial da União, Poder Executivo, Brasília, $2006 c$.

65. Brasil. Ministério da Saúde. Secretaria de Ciência, Tecnologia e Insumos Estratégicos. Departamento de Assistência Farmacêutica. Disponível em: http://10. 1. 1. 213/portal/saude/profissional/visualizar_texto. cfm?idtxt=37037. Acesso em 24 fev. 2012d.

66. Brasil. Ministério da Saúde. Farmácia Popular: Saúde não tem preço. Brasília, 2011. Disponível em: <http://www.saudenaotempreco.com/index.php〉. Acesso em: 4 dez. 2015.

67. Brasil. Ministério da Saúde. Portaria nº 184, de 03 de fevereiro de 2011. Dispõe sobre o Programa Farmácia Popular do Brasil. Diário Oficial da União, Poder Executivo, Brasília, 2011.

68. Pepe, EVD. et al. A judicialização da saúde e os novos desafios da gestão da assistência farmacêutica. Ciência \& Saúde Coletiva, Rio de Janeiro, v. 15, supl. 5, p.2405-2414, 2010.

69. Marin N. et al. Assistência Farmacêutica para gerentes municipais. Rio de Janeiro: OPAS:OMS, 2003.

70. Karnikowski MGO, Nóbrega OT, Naves JOS \& Silver LD. Access to essential drugs in 11 Brazilian cities: a community based evaluation and action method. J Public Health Policy 2004; 25(3/4):288-298.

71. Boing AC, Bertoldi AD, Boing AF, Bastos JL, Peres KG. Acesso a medicamentos no setor público: análise de usuários do Sistema Único de Saúde no Brasil. Cad. Saúde Pública 2013; 29( 4 ): 691-701. 
72. Brasil. Ministério da Saúde. Portaria $n^{\circ}$ 2. 488, de 21 de outubro de 2011. Aprova a Política Nacional de Atenção Básica, estabelecendo a revisão de diretrizes e normas para a organização da Atenção Básica, para a Estratégia Saúde da Família (ESF) e o Programa de Agentes Comunitários de Saúde (PACS). Diário Oficial da União, 2011.

73. Silva RT. Controle de Diabetes Mellitus e Hipertensão Arterial com Grupos de Intervenção Educacional e Terapêutica em segmento ambulatorial de uma Unidade Básica de Saúde. Saúde e Sociedade, v.15, n.3, p.180-189, 2006.

74. Brasil. Secretaria de Vigilância em Saúde. Vigitel Brasil 2011: vigilância de fatores de risco e proteção para doenças crônicas por inquérito telefônico. Brasília, DF: Ed. do Ministério da Saúde, 2012.

75. Travassos C, Viacava F. Utilização e financiamento de serviços de saúde: dez anos de informação das PNAD. Ciência \& Saúde Coletiva, Rio de Janeiro: Associação Brasileira de Saúde Coletiva - Abrasco, v. 16, n. 9, p. 3646, set. 2011. Editorial. Disponível em: . Acesso em: dez. 2014.

76. Travassos C, Viacava F, Laguardia J. Os suplementos saúde na Pesquisa Nacional por Amostra de Domicílios (PNAD) no Brasil. Revista Brasileira de Epidemiologia, Rio de Janeiro: Associação Brasileira de Saúde Coletiva - Abrasco, v. 11, supl. 1, p. 98-112, maio 2008 .

77. Viacava F. Dez anos de informação sobre acesso e uso de serviços de saúde. Cadernos de Saúde Pública, Rio de Janeiro: Fundação Oswaldo Cruz - Fiocruz, Escola Nacional de Saúde Pública Sérgio Arouca - ENSP, v. 26, n. 12, p. 2210-2211, dez. 2010. Editorial. Disponível em: . Acesso em: dez. 2014.

78. Freitas MPS. et al. Amostra mestra para o sistema integrado de pesquisas domiciliares. Rio de Janeiro: IBGE, 2007. 67 p. 
79. Brasil. Ministério da Saúde. Programa de avaliação para a qualificação do Sistema Único de Saúde. Brasília, DF, 2011. 26 p. Disponível em: . Acesso em: dez. 2014.

80. Duncan BB. et al. Mortalidade por doenças crônicas no Brasil: situação em 2009 e tendências de 1991 a 2009. In: SAÚDE Brasil 2010: uma análise da situação de saúde e de evidências selecionadas de impacto de ações de vigilância em saúde. Brasília, DF: Ministério da Saúde, Secretaria de Vigilância em Saúde, Departamento de Análise de Situação em Saúde, 2011. p. 117-134. (Série G. Estatística e informação em saúde).

81. The World Health. Health Systems: improving performance. 205 p. Geneva: World Health Organization - WHO, 2000. 206 p.

82. Brasil. Ministério da Saúde. Pesquisa Nacional sobre Acesso, Utilização e Promoção do Uso Racional de Medicamentos. Componente Populacional (Introdução, Método e Instrumento). Cad. 01. Brasília, DF, 2016.

83. Costa KS. Acesso e uso de medicamentos: inquéritos de saúde como estratégia de avaliac $\square$ ão. 2014. Universidade Estadual de Campinas, Campinas, 2014. 


\begin{abstract}
ANEXO I
I. Aprovação pelo Comitê da Ética e Pesquisa
\end{abstract}

\title{
PARECER CONSUBSTANCIADO DA CONEP
}

\section{DADOS DO PROJETO DE PESQUISA}

Título da Pesquisa: PESQUISA NACIONAL SOBRE ACESSO, UTILIZAÇÃO E PROMOÇÃO DO USO RACIONAL DE MEDICAMENTOS NO BRASIL - PNAUM

Pesquisador: Sotero S Mengue

Sotero S Mengue

Área Temática:

Versão: 3

CAAE: 18947013.6 .0000 .0008

Instituição Proponente: Secretaria de Ciência e Tecnologia e Insumos Estratégicos

Patrocinador Principal: Ministério da Saúde

Ministério da Saúde

\section{DADOS DO PARECER}

Número do Parecer: 633.253

Data da Relatoria: $23 / 04 / 2014$

\section{Apresentação do Projeto:}

A Pesquisa Nacional sobre acesso, utilização e promoção do uso racional de medicamentos no Brasil (PNAUM) foi instituída pela PORTARIA № 2.077, DE 17 DE SETEMBRO DE 2012 do Gabinete do Ministro, Ministério da Saúde levando em consideração a necessidade de conhecer aspectos relacionados ao acesso, utilização e uso racional de medicamentos no Brasil; e os objetivos estratégicos números 11 e 12 estabelecidos no documento "Pesquisas Estratégicas para o Sistema de Saúde (PESS/2011)", do Ministério da Saúde, quais

sejam: "Garantir a assistência farmacêutica no âmbito do Sistema Único de Saúde (SUS)" e "Fortalecer o complexo industrial e de ciência, tecnologia e inovação em saúde como vetor estruturante da agenda nacional de desenvolvimento econômico, social e sustentável, reduzindo a vulnerabilidade do acesso à saúde e a assistência farmacêutica no âmbito do SUS". A execução deste projeto está a cargo da Universidade Federal do Rio Grande do Sul e conta com a participação de pesquisadores do Ministério da Saúde e das instituições listadas a seguir: Escola Nacional de Saúde Pública / Fundação Oswaldo Cruz, Faculdade de Medicina da Santa Casa de Misericórdia de São Paulo, Universidade de Brasília, Universidade Estadual de Campinas, Universidade Federal da Bahia, Universidade Federal de Pelotas, Universidade Federal de Santa Catarina, Universidade Federal de São Paulo, Universidade Federal do Ceará. Trata-se de um 
estudo transversal clássico. Estes estudos podem ser caraterizados como aqueles que incluem como sujeitos todas as pessoas na população, ao tempo da averiguação, ou uma amostra representativa de todas essas pessoas, selecionadas sem levar em consideração o estado de exposição ou de doença. Serão entrevistados indivíduos residentes nos domicílios selecionados, nas regiões Norte, Nordeste, Centro-Oeste, Sudeste e Sul do país. O tamanho da amostra deverá ser estimado com maior precisão no decorrer do detalhamento do plano amostral. A estimativa inicial é de que a amostra seja composta por 38.400 indivíduos, de modo a possibilitar, com grau de confiança estabelecido em parâmetros estatísticos, a generalização dos dados amostrais para o conjunto da população. Os questionários serão aplicados por entrevistadores treinados e com o uso de equipamentos eletrônicos. O instrumento de coleta de dados será constituído pelos seguintes blocos: informações sobre o domicílio, bens domésticos e renda, informações sobre a pessoa de referência da família, informações do entrevistado, plano de saúde e estilo de vida. Serão coletadas informações mais detalhadas sobre as doenças crônicas de alta prevalência e seus cuidados com especial interesse no acesso e uso racional dos medicamentos. Também serão investigadas a utilização dos serviços de farmácia do SUS e do Programa Farmácia Popular do Brasil e as caraterísticas de adesão ao tratamento apresentadas pelos entrevistados. SERVIÇOS: O delineamento da avaliação dos serviços seguirá o mesmo modelo utilizado no inquérito domiciliar com as inclusões, alterações e adaptações necessárias para a dar conta adequadamente das diferenças entre os dois modelos de estudo. A amostra será composta de 75 municípios dos 300 selecionados para o inquérito. Isso corresponde a uma proporção de 1 para 4. Esses 75 municípios serão distribuídos em frações iguais de 15 municípios para cada região do Brasil e, em cada região, serão organizados em três grupos de acordo com o tamanho da população do município sendo, então, cinco municípios de pequenos porte, tercil inferior; cinco municípios de médio porte, tercil médio da distribuição e cindo municípios de grande porte que deverão corresponder ao tercil superior da distribuição da população em cada uma as regiões. Em cada um dos municípios selecionados serão identificadas duas unidades de saúde mais próximas de cada um dos dois setores censitários sorteados para o inquérito domiciliar. Essa estratégia tem como meta avaliar o serviço o mais próximo possível da amostra domiciliar investigada de forma a permitir algum grau de relacionamento entre os serviços, os usuários e os moradores de cada região. O tamanho da amostra estimado para os serviços é de 30 usuários por unidade. Considerando-se 15 municípios por região e duas unidades de saúde por município somam-se 900 entrevistas que é um número aproximado àquele estimado para cada um dos domínios da amostra do inquérito domiciliar. Os usuários serão arrolados de forma consecutiva em pelo menos dois dias e turnos de 
trabalho em que a unidade de saúde estiver em funcionamento para atendimento de qualquer natureza. Caso esse número não seja atingido nesse tempo deverão ser feitas tantas quantas visitas necessárias para atingir a meta amostral. Nos casos de unidades volantes ou que tenham seu funcionamento em período menor ao tempo de permanência da equipe de campo do inquérito domiciliar serão aceitas entrevistas realizadas em um único turno ou dia. Nos casos dos profissionais das unidades será selecionado aquele que estiver presente em um dos turnos das entrevistas com os usuários ou aquele que o tempo gasto para a entrevista tenha o menor impacto no atendimento dos pacientes da unidade. Em cada uma das unidades será avaliada a infraestrutura disponível e os medicamentos armazenados em estoque e para distribuição. Desses medicamentos será selecionada uma amostra ao acaso para a verificação da data de validade do produto. Os gestores e demais responsáveis pela assistência farmacêutica do município serão entrevistados em seu local de trabalho em dia e hora por eles definido. Os dados resultantes do trabalho de campo serão tratados em aplicativos de estatística disponíveis na Universidade Federal do Rio Grande do Sul. Para cada modelagem específica poderão ser utilizados os softwares IBM SPSS, SAS ou Stata. A interpretação dos resultados será desenvolvida com suporte da teoria das probabilidades e da inferência estatística do método quantitativo de pesquisa.

\section{Objetivo da Pesquisa:}

Objetivo Primário:

O objetivo geral consiste em avaliar o acesso e o uso racional de medicamentos pela população brasileira.

\section{Objetivo Secundário:}

Caracterizar a utilização de medicamentos para as doenças mais prevalentes;

Caracterizar os medicamentos segundo os componentes da assistência farmacêutica: medicamentos da atenção básica, medicamentos estratégicos e medicamentos do componente especializado;

Identificar as formas e locais de obtenção de medicamentos incluído o SUS, as farmácias provadas e o programa Farmácia Popular;

Avaliar os indicadores de racionalidade do uso de medicamentos e do grau de seguimento das prescrições em relação à adesão e persistência com o tratamento medicamentoso;

Avaliar o acesso a medicamentos segundo variáveis demográficas, sociais e econômicas. Avaliação a presença de cuidados com as doenças crônicas associadas ao uso de serviços de saúde a ao 
estilo de vida;

Avaliar a organização dos serviços de Atenção Básica na a garantia do acesso e o uso racional de medicamentos da população;

Avaliar possíveis efeitos das políticas públicas de acesso a medicamentos na redução dos gastos individuais com medicamentos e no combate a iniquidade;

Avaliar a Política de Saúde no Brasil referente à Assistência Farmacêutica e sua efetivação na Atenção Básica de Saúde.

\section{Avaliação dos Riscos e Benefícios:}

Segundo o pesquisador:

Riscos:

Por se tratar apenas de entrevista, o risco pode ser considerado muito baixo, apenas o eventual transtorno de responder à entrevista.

Benefícios:

A avaliação do acesso e do uso racional de medicamentos pode fornecer subsídios para tornar a assistência farmacêutica mais efetiva dentro do SUS.

\section{Comentários e Considerações sobre a Pesquisa:}

Trata-se da análise da emenda ao projeto.

Considerações sobre os Termos de apresentação obrigatória:

Vide item "Conclusões ou Pendências e Lista de Inadequações".

\section{Recomendações:}

Vide item "Conclusões ou Pendências e Lista de Inadequações".

\section{Conclusões ou Pendências e Lista de Inadequações:}

A presente emenda ao projeto tem como objetivo:

1- Informar que ingressaram na equipe do presente estudo 3 pesquisadores da Universidade Federal de Minas Gerais - UFMG: Juliana Alvares, Francisco de Assis Acurcio e Augusto Afonso Guerra Junior; 2 - Apresentar os instrumentos de campo que foram revisados e atualizados.

\section{Situação do Parecer:}

Aprovado 


\section{Considerações Finais a critério da CONEP:}

Diante do exposto, a Comissão Nacional de Ética em Pesquisa - CONEP, de acordo com as atribuições definidas na Resolução CNS 466/2012 e na Norma Operacional № 001/2013 do CNS, manifesta-se pela aprovação da emenda ao projeto proposta.

Situação: Emenda aprovada.

BRASILIA, 04 de Maio de 2014

Assinador por:

Jorge Alves de Almeida Venancio

(Coordenador)

Endereço: SEPN 510 NORTE, BLOCO A 1ํ SUBSOLO, Edifício Ex-INAN - Unidade II - Ministério da Saúde SEPN 510 NORTE, BLOCO A 1 SUBSOLO, Edifício Ex-INAN - Unidade II - Ministério da Saúde Bairro: Asa Norte CEP:70.750-

UF: DF Asa Norte CEP:70.750- 
ANEXO II

\title{
PNAUM - Pesquisa Nacional sobre Acesso, Utilização e Promoção do Uso Racional de Medicamentos no Brasil
}

\author{
Questionário do Inquérito Domiciliar
}

Bloco 1 - INFORMAÇÕES DO ENTREVISTADO

Vou começar fazendo algumas perguntas sobre a(o) $\operatorname{Sr}(a)$.

\begin{tabular}{|c|c|c|}
\hline 1.2 & Em qual estado o(a) Sr(a) nasceu? & $\begin{array}{l}\text { [] Acre } \\
\text { [] Alagoas } \\
\text { [] Amapá } \\
\text { [] Amazonas } \\
\text { [] Bahia } \\
\text { [] Ceará } \\
\text { [] Distrito Federal } \\
\text { [] Espírito Santo } \\
\text { [] Goiás } \\
\text { [] Maranhão } \\
\text { [] Mato Grosso } \\
\text { [] Mato Grosso do Sul } \\
\text { [] Minas Gerais } \\
\text { [] Pará } \\
\text { [] Paraíba } \\
\text { [] Paraná } \\
\text { [] Pernambuco } \\
\text { [] Piauí } \\
\text { [] Rio de janeiro } \\
\text { [] Rio Grande do Norte } \\
\text { [] Rio Grande do Sul } \\
\text { [] Rondônia } \\
\text { [] Roraima } \\
\text { [] Santa Catarina } \\
\text { [] São Paulo } \\
\text { [] Sergipe } \\
\text { [] Tocantins } \\
\text { [] Outro país }\end{array}$ \\
\hline $1.2^{\mathrm{a}}$ & Outro país & $99-\mathrm{NS} / \mathrm{NR}$ \\
\hline 1.3 & $\begin{array}{l}\text { Em qual cidade deste estado o(a) } \operatorname{Sr}(\text { a) nasceu? } \\
\text { (ex: Belo Horizonte) }\end{array}$ & $99-\mathrm{NS} / \mathrm{NR}$ \\
\hline 1.4 & É casado(a) ou vive com companheiro(a)? & $\begin{array}{l}\text { [] Sim } \\
\text { [] Não, mas já viveu antes } \\
\text { [] Nunca viveu }\end{array}$ \\
\hline
\end{tabular}




\begin{tabular}{|c|c|c|}
\hline 1.5 & $\begin{array}{l}\text { A sua cor ou raça é: } \\
* \text { Ler as alternativas* }\end{array}$ & $\begin{array}{l}\text { [] Branca } \\
\text { [] Preta } \\
\text { [] Amarela } \\
\text { [] Parda } \\
\text { [] Indígena } \\
\text { [] NS/NR }\end{array}$ \\
\hline 1.6 & $\begin{array}{l}\text { Qual é o seu peso atual? } \\
(K g)\end{array}$ & 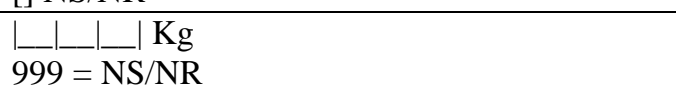 \\
\hline 1.7 & $\begin{array}{l}\text { Qual é a sua altura? } \\
(\mathrm{em} \mathrm{cm})\end{array}$ & $\begin{array}{l}|\ldots| \_|\ldots| \text { centímetros } \\
999=\mathrm{NS} / \mathrm{NR}\end{array}$ \\
\hline 1.8 & Sabe ler e escrever? & $\begin{array}{l}\text { [] Sim } \\
2 \text { [] Não => Passe para 2.1.0 }\end{array}$ \\
\hline 1.9 & $\begin{array}{l}\text { Até que série e grau o(a) } \mathrm{Sr}(\mathrm{a}) \text { estudou? } \\
\text { *Considere as séries completas de estudo* }\end{array}$ & \\
\hline 1.10 & Curso primário & [] $\quad 1$ [ [] 2 [] $3\left[\begin{array}{llll}4 & 4[ & 5 & {[]}\end{array}\right.$ \\
\hline $1.10^{\mathrm{a}}$ & Admissão & \begin{tabular}{l|l}
{[]} & 4[] \\
\end{tabular} \\
\hline $1.10 \mathrm{~b}$ & Curso ginasial ou ginásio & 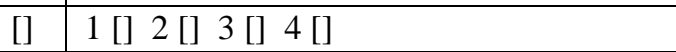 \\
\hline 1.11 & $\begin{array}{l}1^{\circ} \text { grau ou fundamental ou supletivo de primeiro grau } \\
\text { ou EJA }\end{array}$ & 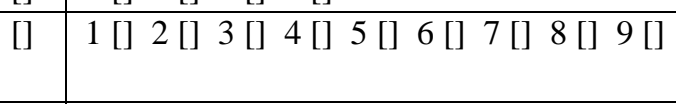 \\
\hline 1.12 & $\begin{array}{l}2^{\circ} \text { grau ou colégio técnico ou normal ou científico ou } \\
\text { ensino médio ou supletivo de segundo grau ou EJA }\end{array}$ & $1[$ [] 2 [] 3 [] \\
\hline 1.13 & $3^{\circ}$ grau ou curso superior & \begin{tabular}{l|l} 
[] & [] Completo \\
& [] Incompleto
\end{tabular} \\
\hline $1.41^{\mathrm{a}}$ & Pós-graduação (especialização, mestrado, doutorado) & [] \\
\hline 1.15 & Nunca estudou & [] \\
\hline 1.16 & NS/NR & [] \\
\hline Sexo & Sexo do entrevistado & $\begin{array}{l}\text { []Masculino } \\
\text { [] Feminino }\end{array}$ \\
\hline Idade & Idade do entrevistado & \\
\hline
\end{tabular}




\section{Bloco 2 - DOENÇAS CRÔNICAS}

\section{DIABETES}

\begin{tabular}{|l|l|}
\hline 2.2 .0 & Algum médico já lhe disse que o(a) Sr(a) tem diabetes ou açúcar
\end{tabular} alto no sangue?

2.2.1 $\quad$ Que idade o(a) Sr(a) tinha na primeira vez que o médico lhe disse que tinha diabetes?

* Caso o entrevistado relate uma idade aproximada, anote a idade aproximada declarada por ele*

\begin{tabular}{l|l} 
2.2.2 & $\mathrm{O}$ (a) $\mathrm{Sr}(\mathrm{a})$ tem indicação médica para usar algum remédio para
\end{tabular} diabetes que não seja a insulina?

[] $\mathrm{Sim}$

[] Não =>Passe para 2.3 .0

|___ anos

$00=$ Se menos de 1 ano

$99=\mathrm{NS} / \mathrm{NR}$

\begin{tabular}{|l|l|l}
\hline 2.2 .2 & $\begin{array}{l}\text { O(a) Sr(a) tem indicação médica para usar algum remédio para } \\
\text { diabetes que não seja a insulina? }\end{array}$ & \\
\hline & Para controlar o diabetes: & \\
\hline 2.2 .3 & O(a) Sr(a) está usando algum destes remédios? & \\
\hline 2.2 .4 & Qual(is)? & \\
\hline $2.2 .4^{\text {a }}$ & Remédio 1 & \\
\hline $2.2 .4 \mathrm{~b}$ & Remédio 2 & \\
\hline $2.2 .4 \mathrm{c}$ & Remédio 3 & \\
\hline 2.2 .5 & Nośltimos 30 dias, o(a) Sr(a) ficous algum destes remédios
\end{tabular}

\begin{tabular}{|l|l|}
\hline 2.2 .5 & Nos últimos 30 dias, o(a) $\mathrm{Sr}$ (a) ficou sem algum destes remédios
\end{tabular} por algum tempo?

[] Sim

[] Não =>Passe para 2.2.6

[] $\mathrm{Sim}$

[] Não =>Passe para 2.2.6

*Listar abaixo os remédios*

\begin{tabular}{|l|l|}
\hline $2.2 .5^{\mathrm{a}}$ & $\begin{array}{l}\text { Qual(is)? } \\
\text { *Preencha os campos correspondentes aos remédios que o } \\
\text { entrevistado relatou que deixou de tomar* }\end{array}$ \\
\hline & Remédio 1: \\
\hline
\end{tabular}

\begin{tabular}{|l|l|l|}
\hline $2.2 .5 \mathrm{~b}$ & Por quanto tempo? & \\
\hline $2.2 .5 \mathrm{c}$ & Por que ficou sem este remédio? &
\end{tabular}

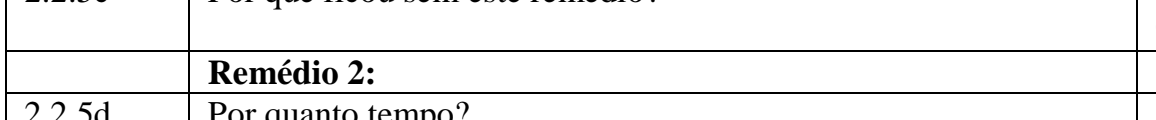

\begin{tabular}{|l|l|l}
\hline $2.2 .5 \mathrm{~d}$ & Por quanto tempo? & \\
\hline $2.2 .5 \mathrm{e}$ & Por que ficou sem este remédio? & \\
\hline & Remédio 3: & \\
\hline $2.2 .5 \mathrm{f}$ & Por quanto tempo? & \\
\hline $2.2 .5 \mathrm{~g}$ & Por que ficou sem este remédio? & ? \\
\hline &
\end{tabular}

\begin{tabular}{|l|l|l}
\hline 2.2 .6 & $\mathrm{O}(\mathrm{a}) \mathrm{Sr}(\mathrm{a})$ tem indicação médica para usar insulina? & [] \\
& & [] \\
\hline
\end{tabular}

\begin{tabular}{|l|l|l}
\hline $2.2 .6^{\mathrm{a}}$ & $\mathrm{O}(\mathrm{a}) \mathrm{Sr}(\mathrm{a})$ usa insulina? & \\
& \\
\hline
\end{tabular}

\begin{tabular}{|l|l|l|}
\hline $2.2 .6 \mathrm{~b}$ & Qual é o nome da insulina que o(a) sr(a) usa? & \\
\hline $2.2 .6 \mathrm{c}$ & Data de validade: & \\
\hline 2.2 .7 & Quantas vezes ao dia? & \\
& \\
\hline 2.2 .8 & Qual horário? & \\
& & \\
\hline $2.2 .8^{\mathrm{a}}$ & Qual? & \\
\hline
\end{tabular}

[] $\mathrm{Sim}$

[] Não => Passe para 2.2 .6

[] NS/NR => Passe para 2.2 .6

[] Remédio 1

[] Remédio 2

[] Remédio 3

L___ dias $99=\mathrm{NS} / \mathrm{NR}$

$99=\mathrm{NS} / \mathrm{NR}$

L___ dias $99=\mathrm{NS} / \mathrm{NR}$ $99=\mathrm{NS} / \mathrm{NR}$

L___ dias $99=\mathrm{NS} / \mathrm{NR}$

$99=\mathrm{NS} / \mathrm{NR}$

[] $\mathrm{Sim}$

[] Não => Passe para 2.2.18

[] NS/NR => Passe para 2.2.18

[] $\mathrm{Sim}$

[] Não => Passe para 2.2.18

[] NS/NR $=>$ Passe para 2.2 .18

|___/l ____ mês/ano

$\mathbf{9 9}=\mathbf{N S} / \mathbf{N R}$

[] Apenas uma vez

[] Duas ou mais vezes $=>$ Passe para 2.2.9

[] Tantas quanto necessário $=>$ Passe para 2.2.9

[] Manhã => Passe para 2.2.9

[] Noite => Passe para 2.2.9

[] Outro

[] NS/NR 


\begin{tabular}{|c|c|c|}
\hline 2.2 .9 & $\begin{array}{l}\text { Como o(a) } \mathrm{Sr}(\text { a) adquire as seringas e agulhas que utiliza para } \\
\text { aplicar a insulina? }\end{array}$ & $\begin{array}{l}\text { - [] Compra => Passe para } 2.2 .9 b \\
\text { - [] Ganha do SUS => Passe para } 2.2 .9 b \\
\text { - [] Outro } \\
\text { - [] NS/NR => Passe para } 2.2 .9 b\end{array}$ \\
\hline $2.2 .9^{\mathrm{a}}$ & Como? & \\
\hline $2.2 .9 \mathrm{~b}$ & $\begin{array}{l}\text { O(a) Sr(a) utiliza as mesmas seringas e agulhas mais de uma } \\
\text { vez? }\end{array}$ & $\begin{array}{l}\text { [] Sim } \\
\text { [] Não } \\
\text { []Às vezes } \\
\text { [] NS/NR }\end{array}$ \\
\hline $2.2 .10^{\mathrm{a}}$ & Antes de usar insulina, faz teste de glicose, ou açúcar no sangue? & $\begin{array}{l}\text { [] Sim } \\
\text { [] Não => Passe para } 2.2 .14 \\
\text { [] Às vezes }\end{array}$ \\
\hline $2.2 .10 \mathrm{~b}$ & Quantas vezes costuma fazer o teste de glicose por dia? & 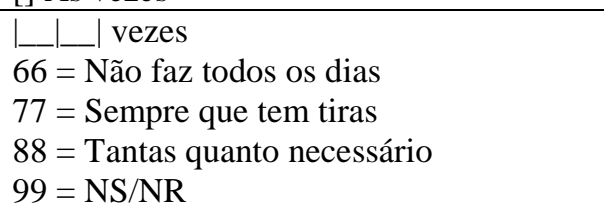 \\
\hline $2.2 .11^{\mathrm{a}}$ & $\mathrm{O}$ (a) $\mathrm{Sr}(\mathrm{a})$ possui o aparelho para medir a glicose? & $\begin{array}{l}\text { [] Sim } \\
\text { [] Não => Passe para } 2.2 .14 \\
\text { [] NS/NR => Passe para } 2.2 .14\end{array}$ \\
\hline $2.2 .11 \mathrm{~b}$ & Como o(a) $\mathrm{Sr}(\mathrm{a})$ obteve este aparelho? & $\begin{array}{l}\text { - [] Comprou => Passe para 2.2.12 } \\
\text { - [] Ganhou do SUS => Passe para } 2.2 .12 \\
\text { - [] Outro } \\
\text { - [] NS/NR => Passe para } 2.2 .12\end{array}$ \\
\hline $2.2 .11 \mathrm{c}$ & Como? & \\
\hline 2.2 .12 & Como o(a) $\mathrm{Sr}(\mathrm{a})$ adquire as tiras para o aparelho? & $\begin{array}{l}\text { - [] Compra => Passe para } 2.2 .13 \\
\text { - [] Ganha do SUS => Passe para } 2.2 .13 \\
\text { - [] Outro } \\
\text { - [] NS/NR => Passe para } 2.2 .13\end{array}$ \\
\hline $2.2 .12^{\mathrm{a}}$ & Como? & \\
\hline 2.2 .13 & $\begin{array}{l}\mathrm{O}(\mathrm{a}) \mathrm{Sr}(\mathrm{a}) \text { utiliza as mesmas tiras para o aparelho mais de uma } \\
\text { vez? }\end{array}$ & $\begin{array}{l}\text { [] Sim } \\
\text { [] Não } \\
\text { [] Às vezes } \\
\text { [] NS/NR }\end{array}$ \\
\hline 2.2 .14 & $\begin{array}{l}\text { Algum médico, farmacêutico lhe explicou como utilizar a } \\
\text { insulina? }\end{array}$ & $\begin{array}{l}\text { [] } \mathrm{Sim} \\
\text { [] Não } \\
\text { [] NS/NR }\end{array}$ \\
\hline 2.2 .15 & $\begin{array}{l}\text { Alguém já lhe explicou sobre a possibilidade da glicose, ou } \\
\text { açúcar no sangue, baixar muito? }\end{array}$ & $\begin{array}{l}\text { [] Sim } \\
\text { [] Não } \\
\text { [] NS/NR }\end{array}$ \\
\hline 2.2 .16 & $\begin{array}{l}\mathrm{O}(\mathrm{a}) \mathrm{Sr}(\mathrm{a}) \text {, ou os seus familiares, sabem o que fazer quando a } \\
\text { glicose baixa muito? }\end{array}$ & $\begin{array}{l}\text { [] Sim } \\
\text { [] Não } \\
\text { [] NS/NR }\end{array}$ \\
\hline 2.2 .17 & $\begin{array}{l}\text { Nos últimos } 30 \text { dias, o(a) } \operatorname{Sr}(\text { a) ficou sem usar insulina por algum } \\
\text { tempo? }\end{array}$ & $\begin{array}{l}\text { [] Sim } \\
\text { [] Não => Passe para } 2.2 .18 \\
\text { [] NS/NR => Passe para } 2.2 .18\end{array}$ \\
\hline $2.2 .17^{\mathrm{a}}$ & Por quanto tempo? & $\begin{array}{l}\left.\right|_{-1}|\ldots| \text { dias } \\
99=\mathrm{NS} / \mathrm{NR}\end{array}$ \\
\hline $2.2 .17 \mathrm{~b}$ & Qual foi o motivo? & \\
\hline 2.2 .18 & $\begin{array}{l}\text { Tem algum remédio, que o(a) } \operatorname{Sr}(\text { a) deveria estar usando, nos } \\
\text { últimos } 30 \text { dias, para a diabetes, e não está? }\end{array}$ & $\begin{array}{l}\text { [] Sim } \\
\text { [] Não =>Passe para } 2.2 .20 \\
\text { [] NS/NR =>Passe para } 2.2 .20\end{array}$ \\
\hline 2.2 .19 & $\begin{array}{l}\text { Qual(is) os remédios que o(a) } \operatorname{Sr}(\text { a) deveria estar usando e não } \\
\text { está? }\end{array}$ & *Listar abaixo os remédios* \\
\hline $2.2 .19^{\mathrm{a}}$ & Remédio 4 & \\
\hline $2.2 .19 \mathrm{~b}$ & Por que ficou sem usar este remédio? & $99=\mathrm{NS} / \mathrm{NR}$ \\
\hline $2.2 .19 \mathrm{c}$ & Remédio 5 & \\
\hline
\end{tabular}




\begin{tabular}{|c|c|c|}
\hline $2.2 .19 \mathrm{~d}$ & Por que ficou sem usar este remédio? & $99=\mathrm{NS} / \mathrm{NR}$ \\
\hline $2.2 .19 \mathrm{e}$ & Remédio 6 & \\
\hline $2.2 .19 \mathrm{f}$ & Por que ficou sem usar este remédio? & $99=\mathrm{NS} / \mathrm{NR}$ \\
\hline 2.2 .20 & $\mathrm{O}$ (a) $\mathrm{Sr}(\mathrm{a})$ faz dieta para diabetes? & $\begin{array}{l}\text { [] Sim } \\
\text { [] Não } \\
\text { [] Às vezes } \\
\text { [] NS/NR }\end{array}$ \\
\hline 2.2 .21 & $\begin{array}{l}\text { Algum médico já lhe disse que o diabetes causou algum } \\
\text { problema de saúde no(a) } \operatorname{Sr}(\text { a)? }\end{array}$ & $\begin{array}{l}\text { [] Sim } \\
\text { [] Não =>Passe para } 2.2 .23 \\
\text { [] NS/NR =>Passe para } 2.2 .23\end{array}$ \\
\hline 2.2 .22 & $\begin{array}{l}\text { Qual(is) problema(s)? } \\
\text { *Ler as alternativas* }\end{array}$ & $\begin{array}{l}\text { - [] Problema de vista/visão? =>Passe para } 2.2 .23 \\
\text { - [] Problema nos rins? =>Passe para 2.2.23 } \\
\text { - [] Problema circulatório, pé diabético? =>Passe par } \\
\text { 2.2.23 } \\
\text { - [] Problema de cicatrização? =>Passe para } 2.2 .23 \\
\text { - [] Outro? } \\
\text { - [] NS/NR =>Passe para } 2.2 .23\end{array}$ \\
\hline $2.2 .22^{\mathrm{a}}$ & Qual? & \\
\hline 2.2 .23 & $\begin{array}{l}\text { No dia a dia, quanto o diabetes limita as suas atividades } \\
\text { habituais? } \\
\text { *Ler as alternativas* }\end{array}$ & $\begin{array}{l}\text { [] Não limita } \\
\text { [] Um pouco } \\
\text { [] Moderadamente } \\
\text { [] Intensamente } \\
\text { [] Muito intensamente }\end{array}$ \\
\hline
\end{tabular}


Agora vamos falar sobre os remédios que o(a) $\operatorname{Sr}($ a) usa para o tratamento das doenças que o(a) $\operatorname{Sr}(a)$ citou.

\section{FICHA DE REMÉDIOS DE USO CRÔNICO}

\begin{tabular}{|c|c|c|}
\hline MC.1 & $\begin{array}{l}\text { Para o tratamento de qual(is) doença(s) o(a) } \\
\text { entrevistado(a) utiliza este remédio: }\end{array}$ & $\begin{array}{l}\text { - [] Hipertensão => Passe para } \\
\text { MC.2 } \\
\text { - [] Diabetes => Passe para MC.2 } \\
\text { - [] Doenças do coração => Passe } \\
\text { para MC.2 } \\
\text { - [] Colesterol alto => Passe para } \\
\text { MC.2 } \\
\text { - [] AVC => Passe para MC.2 } \\
\text { - [] Asma, bronquite, (DPBOC) => } \\
\text { Passe para MC.2 } \\
\text { - [] Artrite ou reumatismo => Passe } \\
\text { para MC.2 } \\
\text { - [] Depressão => Passe para MC.2 } \\
\text { - [] Outras doenças crônicas } \\
\text { - [] NS/NR => Passe para } \text { MC.2 }\end{array}$ \\
\hline MC.1 ${ }^{\mathrm{a}}$ & Outras doenças crônicas: & \\
\hline MC.2 & $\begin{array}{l}\text { Tem alguma embalagem? } \\
\text { *Observar } \boldsymbol{e} \text { preencher* } \\
\text { *Considere como embalagem a caixa, cartela, } \\
\text { bisnaga ou outro recipiente que contenha o } \\
\text { remédios e suas informações* }\end{array}$ & $\begin{array}{l}\text { [] Sim } \\
\text { [] Não => Passe para MC.5 }\end{array}$ \\
\hline MC.3 & $\begin{array}{l}\text { O remédio é genérico? } \\
\text { *Observar e preencher* } \\
\text { (Tarja amarela com G, Lei } \\
9787 \text { ) }\end{array}$ & $\begin{array}{l}\text { [] Sim } \\
\text { [] Não } \\
\text { [] NS/NR }\end{array}$ \\
\hline MC.4 & $\begin{array}{l}\text { Data de validade } \\
\qquad \text { *Observar e preencher* }\end{array}$ & $\begin{array}{l}|+| \_|/| \_\left|\_\right| \text {mês/ano } \\
99-N S / N R\end{array}$ \\
\hline MC.5 & $\begin{array}{l}\text { Forma Farmacêutica } \\
\text { *Observar e preencher* } \\
\text { Se respondido “[] Pomada, creme, gel, bisnaga ou } \\
\text { spray de pele => } \\
\text { Passe para MC.6 “, não deverá aparecer a } \\
\text { questão MC.8 }\end{array}$ & 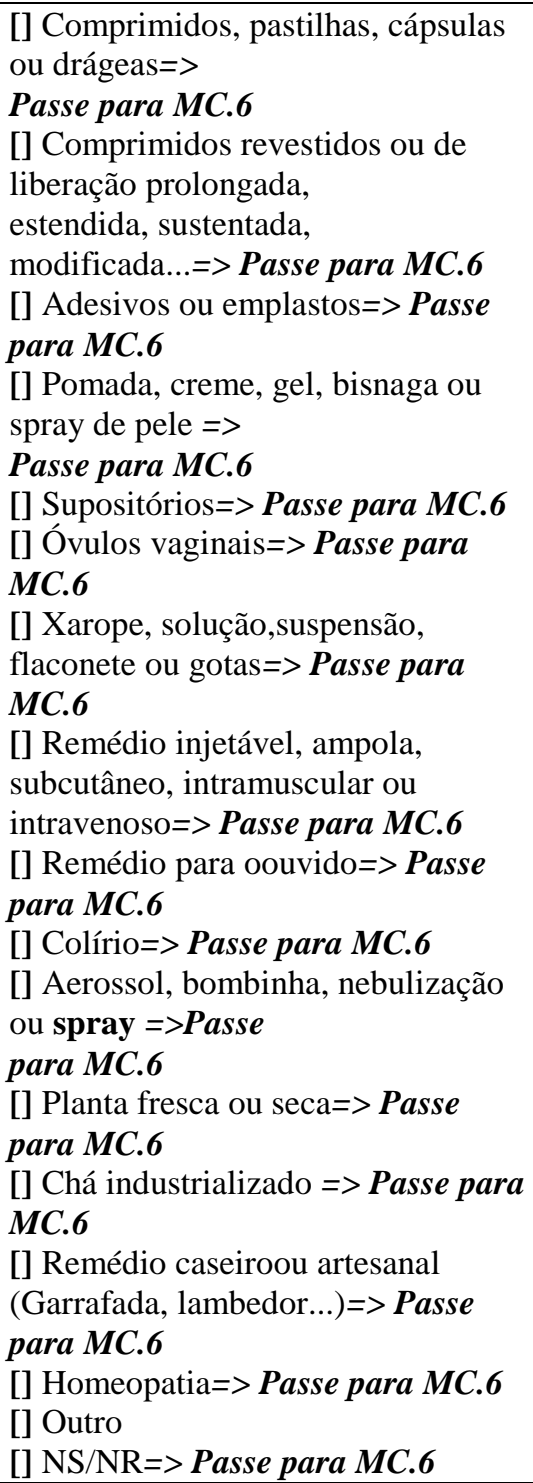 \\
\hline MC.5 $^{\mathrm{a}}$ & Se outro, qual: & $99-\mathrm{NS} / \mathrm{NR}$ \\
\hline MC.6 & Qual é a concentração deste remédio? & $\begin{array}{l}\text { *Desconsiderar as unidades de } \\
\text { concentração, anotar apenas os }\end{array}$ \\
\hline
\end{tabular}





\section{PREENCHER SEM PERGUNTAR:}

\section{Entrevistado(a) possui alguma doença}

crônica?

[] Sim, apenas uma

[] Sim, mais de uma => Passe para 3.9

[] Não => Passe para 4.0

\section{Bloco 10 - PLANO DE SAÚDE}

Agora, vou fazer algumas perguntas referentes a planos de saúde.

\begin{tabular}{|c|c|c|}
\hline 1.10. & 2.O(a) Sr(a) tem plano de saúde ou convênio médico? & $\begin{array}{l}\text { [] Sim } \\
\text { [] Não =>Encerre o bloco } \\
\text { [] Não sabe =>Encerre o bloco }\end{array}$ \\
\hline 10.2 & Qual o nome do(s) plano(s) de saúde ou convênio(s)? & \\
\hline 10.3 & $\mathrm{O}$ (a) $\mathrm{Sr}(\mathrm{a})$ é o titular deste plano? & $\begin{array}{l}\text { [] Sim } \\
\text { [] Não }\end{array}$ \\
\hline & $\mathrm{O}(\mathrm{s})$ plano(s) ou convênio(s) cobre $(\mathrm{m})$ : & \\
\hline 10.4 & $\begin{array}{l}\text { Consulta médica? } \\
\text { *COPAGAMENTO: O entrevistado paga apenas uma } \\
\text { parte da consulta* }\end{array}$ & $\begin{array}{l}\text { [] Não } \\
\text { [] Tenho desconto no preço } \\
\text { [] O plano cobre, mas tem copagamento } \\
\text { [] O plano cobre integral } \\
\text { [] Eu pago e o plano reembolsa } \\
\text { [] NS/NR }\end{array}$ \\
\hline 10.5 & $\begin{array}{l}\text { Internação? } \\
\text { *COPAGAMENTO: O entrevistado paga apenas uma } \\
\text { parte da internação* }\end{array}$ & $\begin{array}{l}\text { [] Não } \\
\text { [] Tenho desconto no preço } \\
\text { [] O plano cobre, mas tem copagamento } \\
\text { [] O plano cobre integral } \\
\text { [] Eu pago e o plano reembolsa } \\
\text { [] NS/NR }\end{array}$ \\
\hline 10.6 & $\begin{array}{l}\text { Exames? } \\
\text { *COPAGAMENTO: O entrevistado paga apenas uma } \\
\text { parte do exame* }\end{array}$ & $\begin{array}{l}\text { [] Não } \\
\text { [] Tenho desconto no preço } \\
\text { [] O plano cobre, mas tem copagamento } \\
\text { [] O plano cobre integral } \\
\text { [] Eu pago e o plano reembolsa } \\
\text { [] NS/NR }\end{array}$ \\
\hline 10.7 & $\begin{array}{l}\text { Remédios (fora da internação)? } \\
\text { *COPAGAMENTO: O entrevistado paga apenas uma } \\
\text { parte do remédio* }\end{array}$ & $\begin{array}{l}\text { [] Não => Encerre o bloco } \\
\text { [] Alguns remédios } \\
\text { [] Tenho desconto no preço => Encerre o bloco } \\
\text { [] O plano cobre, mas tem copagamento=> Encerre } \\
\text { o bloco } \\
\text { [] O plano cobre integral }=>\text { Encerre o bloco } \\
\text { [] Eu pago e o plano reembolsa }=>\text { Encerre o bloco } \\
\text { [] NS/NR => Encerre o bloco }\end{array}$ \\
\hline $10.7 \mathrm{a}$ & $\begin{array}{l}\text { Para quais doenças são os remédios que o(s) plano(s) ou } \\
\text { convênio(s) cobre }(\mathrm{m}) \text { ? }\end{array}$ & $\begin{array}{l}99-\mathrm{NS} / \mathrm{NR} \\
=>\text { Encerre o bloco }\end{array}$ \\
\hline
\end{tabular}


PREENCHER SEM PERGUNTAR:

Os dados sobre o domicílio já foram preenchidos por algum outro morador?

[] Sim => Passe para 11.32

[] Não

Agora, preciso de algumas informações sobre este domicílio.

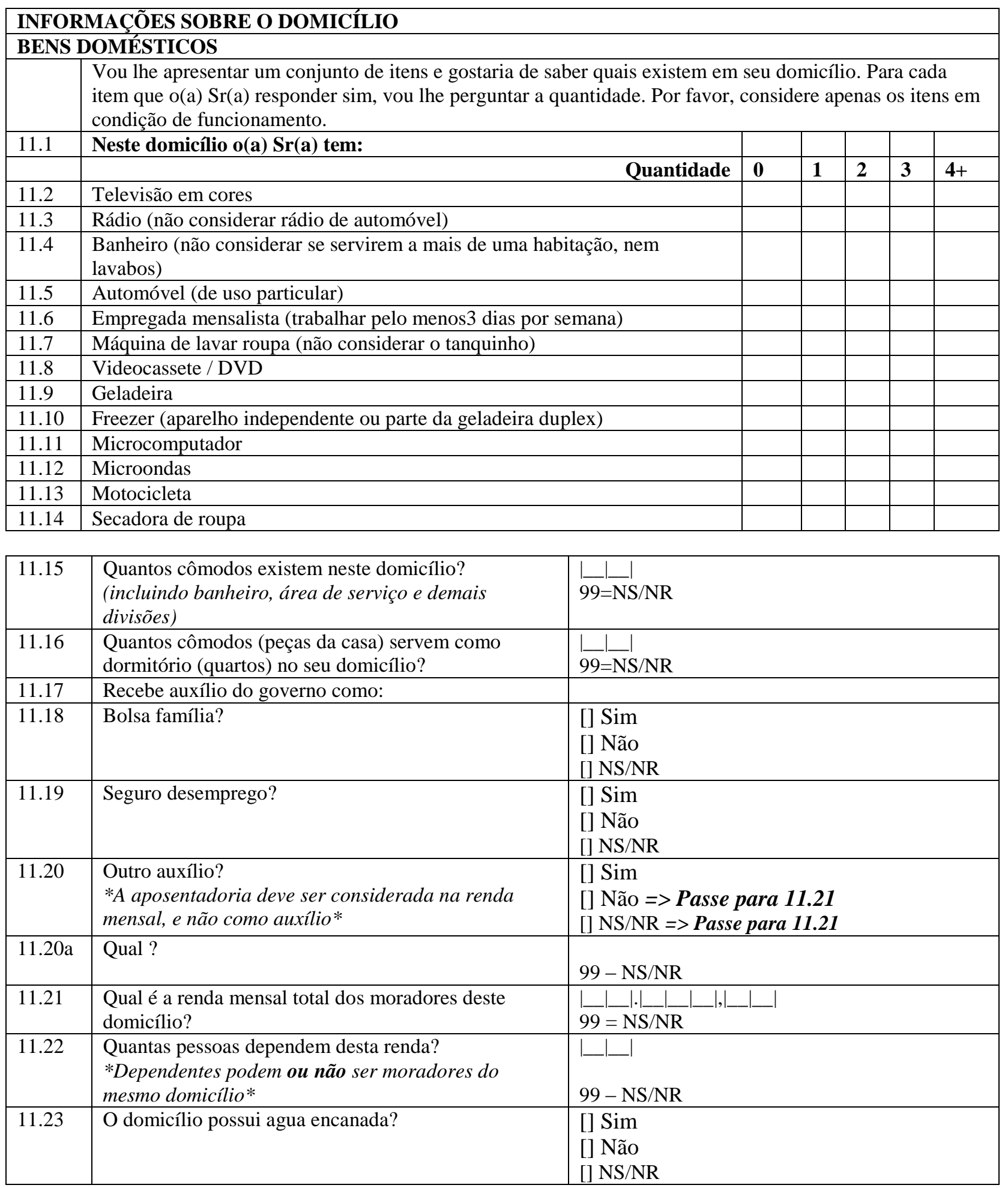




\begin{tabular}{|c|c|c|}
\hline 11.24 & A rua é pavimentada? & $\begin{array}{l}\text { [] Sim } \\
\text { [] Não } \\
\text { [] NS/NR }\end{array}$ \\
\hline 11.25 & $\begin{array}{l}\text { No último ano, a família deixou de comprar algo } \\
\text { importante para o seu dia a dia, precisou fazer algum } \\
\text { empréstimo, ou vendeu algo para pagar gastos com } \\
\text { algum problema de saúde? }\end{array}$ & $\begin{array}{l}\text { [] Sim } \\
\text { [] Não => Passe para } 11.28 \\
\text { [] NS/NR => Passe para } 11.28\end{array}$ \\
\hline 11.26 & Que tipo de problema ocasionou este gasto? & $\begin{array}{l}\text { - [] Remédios=> Passe para } 11.27 \\
\text { - [] Consulta médica => Passe para } 11.27 \\
\text { - [] Exame de laboratório ou imagem => Passe } \\
\text { para } 11.27 \\
\text { - [] Internação clínica => Passe para } 11.27 \\
\text { - [] Cirurgia => Passe para 11.27 } \\
\text { - [] Outro } \\
\text { - [] NS/NR => Passe para 11.27 }\end{array}$ \\
\hline $11.26 \mathrm{a}$ & Se outro, qual: & $99-\mathrm{NS} / \mathrm{NR}$ \\
\hline 11.27 & Como foi que a família lidou com esse gasto? & $\begin{array}{l}\text { - [] Deixou de comprar alimento => Passe para } \\
\text { 11.28 } \\
\text { - [] Deixou de pagar contas => Passe para } 11.28 \\
\text { - [] Fez empréstimo de amigo ou familiar => } \\
\text { Passe para 11.28 } \\
\text { - [] Fez empréstimo de banco oufinanceira => } \\
\text { Passe para 11.28 } \\
\text { - [] Vendeu algum bem => Passe para } 11.28 \\
\text { - [] Outro } \\
\text { - [] NS/NR => Passe para 11.28 }\end{array}$ \\
\hline $11.27 \mathrm{a}$ & Se outro, qual: & $99-\mathrm{NS} / \mathrm{NR}$ \\
\hline
\end{tabular}


